\title{
SURVEY OF NURSES' ATTITUDES TOWARD \\ PHARMACY \\ IN SELECTED ARIZONA HOSPITALS
}

by

Keith Kendon Anderson

A Thesis Submitted to the Faculty of the

COLLEGE OF PHARMACY

In Partial Fulfillment of the Requirements

For the Degree of

MASTER OF SCIENCE

In the Graduate College

THE UNIVERSITY OF ARIZONA 


\section{STATEMENT BY AUTHOR}

This thesis has been submitted in partial fulfillment of requirements for an advanced degree at The University of Arizona and is deposited in the University Library to be made available to borrowers under rules of the Library.

Brief quotations from this thesis are allowable without special permission, provided that accurate acknowledgment of source is made. Requests for permission for extended quotation from or reproduction of tinis manuscript in whole or in part may be granted by the head of the major department or the Dean of the Graduate College when in his judgment the proposed use of the material is in the interest of scholarship. In all other instances, however, permission must be obtained from the author.

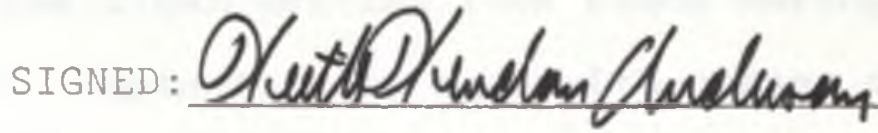

\section{APPROVAL BY THESIS DIRECTOR}

This thesis has been approved on the date shown below:
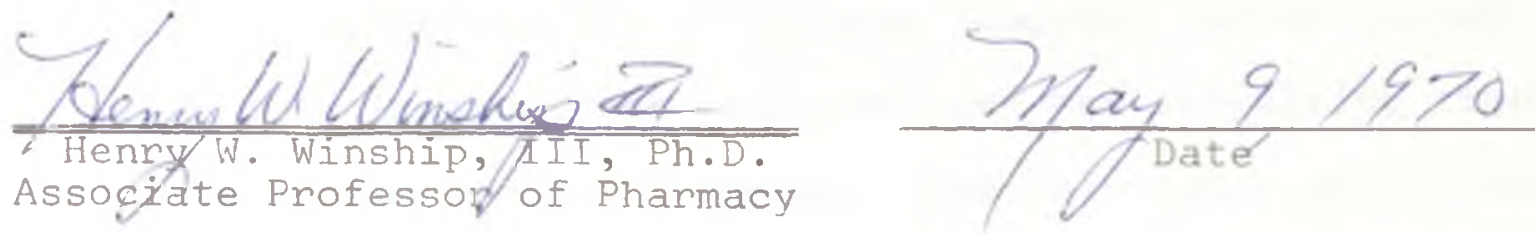


\section{PREFACE}

This research was motivated while the author was working as a staff pharmacist in a large teaching hospital. It seemed that the nurses were the professionals in the hospital with whom the pharmacists had the most frequent interactions. It also seemed that the pharmacists and nurses did not understand very much about each other. Most interactions were in the form of telephone conversations, notes, and memos.

Preliminary work on the research was started in the summer of 1968 and the final writing took place during late 1969 and early 1970. Contacts were made with nurses of various positions and specialties. Their encouragement provided much impetus to complete the project. Special gratitude is extended to all of the nurses who gave of their time and energy to complete the questionnaires.

The members of the thesis committee, who represented the disciplines of pharmacy, nursing, and management unselfishly donated many hours, along with the thesis advisor. The University of Arizona Computer Center played a najor role in supplying computer time and consulting time, since the project was not funded. The University of Arjzona College of Pharmacy provided material and secretary time in the distribution and collection of questionnaires. 
TABLE OF CONTENTS

Page

LIST OF ILLUSTRATIONS . . . . . . . . . . . . . . . . . vi vi

LIST OF TABLES. . . . . . . . . . . . . . . . . . . . $x$

ABSTRACT. . . . . . . . . . . . . . . . xii

1. INTRODUCTION. . . . . . . . . . . . . . . I

Need and Purpose. . . . . . . . . . . . . 1

Working Hypothesis. . . . . . . . . . . . 4

Methodology . . . . . . . . . . . . . . 5

Preliminary Survey. . . . . . . . . . . 5

Final Survey. . . . . . . . . . . . . 8

2. DISCUSSION. . . . . . . . . . . . . . 14

Description of Hospitals. . . . . . . . . . . 14

Findings of Preliminary Nurse Survey. . . . . . 16

Final Survey. . . . . . . . . . . . . . 23

Significance and Correlation Studies. . . . 23

Results.............. 24

3. SUMMARY, CONCLUSIONS; RECOMMENDATIONS .......73

Summary and Conclusions . . . . . . . . . 73

Significant Differences between Groups

of Nurses............... 76

Pharmacist Survey . . . . . . . . . . 81

Recommendations... . . . . . . . . . . 82

APPENDIX A: QUESTIONNAIRE USED IN PRELIMINARY

SURVEY ................... 84

APPENDIX B: QUESTIONNAIRE USED IN FINAL SURVEY • • . . 92

APPENDIX C: SAMPLE CODING SHEET USED IN FINAL SURVEY . . . . . . . . . . . . . . . . .

APPENDIX D: SAMPLE HOLLERITH CARD USED IN FINAL SURVEY 


\section{TABLE OF CONTENTS--Continued}

Page

APPENDIX E: SAMPLE COMPUTER OUTPUT, FINAL SURVEY . . 103 APPENDIX F: QUESTIONNAIRE USED IN PHARMACIST

SURVEY . . . . . . . . . . . . . 105

SELECTED BIBLIOGRAPHY . . . . . . . . . . . . . III 


\section{LIST OF ILLUSTRATIONS}

Figure

Page

1. Flowchart Showing Procedure for Handling Preliminary Survey. . . . . . . . . . . 6

2. Systems Flowchart for Handling Data on Final Survey. . . . . . . . . . . . . .

3. Nurses on the 11-7 Shift Reporting Adequate Information from Pharmacy. Hospital (1)

Compared to Others. . . . . . . . . . .

4. Nurses on the 7-3 Shift Reporting Adequate Information from Pharmacy. Hospital (1)

Compared to Others. . . . . . . . . .

5. Per Cent of Nurses in Each Hospital Choosing

Best Source of Information. . . . . . . .

6. Per Cent of Nurses in Each Experience Group Choosing Pharmacy As the Best Source of Information . . . . . . . . . . . . .

7. Per Cent of Nurses in Each Tenure Group Selecting Pharmacy As the Best Source of Information . . . . . . . . . . . . . . .

8. Per Cent of Nurses Saying Pharmacy Is the

Best Source of Information, Comparing Medical Nurses to the Rest of the

9. Per Cent of Nurses Saying Physicians' Desk

Reference Is the Best Source of Information, Comparing Medical Nurses to the Rest of the Population. . . . . . . . . . . . . . . .

10. Per Cent Nurses on Each Shift Reporting No Need to Talk to a Pharmacist . . . . . .

11. Per Cent Nurses on the 11-7 Shifts Reporting No Need to Talk to a Pharmacist, Hospital (1) Compared with Combined Results of Other Hospitals . . . . . . . . . . . . . . . 
LIST OF ILLUSTRATIONS--Continued

Figure

Page

12. Per Cent Response of All Nurses Indicating if They Could Ever Learn All They Should

Know about the Medications They Administer. .

13. Per Cent Response of Nurses in Each Hospital

Who Thought the Patient Would Benefit if

They Were Strictly Medication Nurses. . . .

14. Per Cent of Medical Nurses in Hospitals (1)

and (4) Who Felt the Patient Would Benefit

if They Were Strictly Medication Nurses,

Compared with other Nurses in the Same

Hospitals . . . . . . . . . . . . . .

15. Per Cent Nurses Responding to whether

Pharmacists Are Needed and Should Be

Concerned with what Happens at the

Nursing Unit. . . . . . . . . . . . .

16. Per Cent of II-7 Nurses Saying Pharmacists

Should Be Unconcerned with Problems of

Nurses, Hospital (1) Compared with Other

Hospitals

17. Per Cent Nurses Indicating the Two Activities

Most Unrelated to the Duties of a Nurse . .

18. Per Cent Nurses Indicating the Two Activities

Most Unrelated to Their Duties, As a

Function of Experience. . . . . . . . . . .

19. Per Cent of Total Population of Nurses

Indicating How Often They Confer with a

Pharmacist for Drug Information . . . . . .

20. Per Cent of Nurses in Each Hospital Who

Confer Often with Pharmacists . . . . . .

21. Per Cent of Nurses Grouped by Tenure Saying

They Conferred often with a Pharmacist

for Drug Information. . . . . . . . . . .

22. Areas in Which Nurses Felt Least Adequate, Per

Cent of Population Selecting Each Area. . . 
viii

LIST OF ILLUSTRATIONS--Continued

Figure

Page

23. Per Cent of Nurses Choosing Each Rating As They Evaluated the Pharmacy Services.

24. Per Cent of Nurses in Each Experience Interval Who Rated the Pharmacy Services

"Excellent" . . . . . . . . . . . . . .

25. Per Cent of Nurses in Each Tenure Interval Who Rated the Pharmacy Services "Excellent".

26. Per Cent of All Nurses Indicating if They Felt Pharmacy and Nursing Should Work Together. The Two Most Frequently Selected Answers Depicted. . . . . . . . . . . . . . .

27. Per Cent of All Nurses Indicating if Pharmacists Were Interested in the Rest of the Hospital and if Pharmacists Were Well Informed. The Two Most Frequently Selected Answers Depicted. . . . . . . . . . . . .

28. Per Cent of 3-11 Shift Nurses Compared with

All Other Nurses As They Perceived Pharmacists Not Being Interested in What Happened in the Rest of the Hospital . . . . . . . .

29. Per Cent of Each Experience Group of Nurses

That Perceived Pharmacists As Being

Interested in what Happened in the Rest

of the Hospital . . . . . . . . . . . . .

30. Per Cent of Nurses in Each Hospital That Chose "Accuracy" As the Most Desinable Quality of a Pharmacist . . . . . . . . .

31. Per Cent of Nurses at Each Level of Supervision Who Chose "Cooperative" As the Most Desirable Quality of a Pharmacist . . . . .

32. Percentages of All Medical and Surgical Nurses Placing Importance on Knowledge about Drugs and the Technical Aspects of Work As Desirable Qualities of Pharmacists. . . . .

33. Per Cent of All Nurses Identifying Each Cause of Most Problems with Pharmacy. . . . . . 


\section{LIST OF ILLUSTRATIONS--Continued}

Figure

Page

34. Per Cent of Nurses in Each Tenure Group Identifying "No Problems" with Pharmacy or "Technicalities and Rules" As Causes of Problems . . . . . . . . . . . . . . 


\section{LIST OF TABLES}

Table

Page

1. Numbers of Nurses Responding to Surveys

by Groups . . . . . . . . . . . . . . . . .

2. Numbers of Nurses Responding to Final Questionnaire from Each Hospital. . . . . 13

3. The Extent to Which Nurses Feel the Pharmacy Is Helpful and/or Bothered When Called. . . . 31

4. Per Cent Responses from Nurses on All Shifts

to Desirable Time During Shift for

Pharmacist to Visit Nursing Unit. . . . . . .

5. Per Cent Responses of Nurses by Specialties Indicating if They Could Ever Learn All They Should know about the Medications They Administer . . . . . . . . . . . . . .

6. Numbers of Nurses Grouped by Relative Emphasis in Work Indicating if They Could Ever Learn All They Should know about the Drugs They Administer.

7. Contingency Table of Intensive Care Nurses in Hospitals (1) and (4) and the Intensive Care Nurses in the Rest of the Hospitals As They Indicated whether the Patient Would Benefit from a lledication Nurse Specialty . . 39

8. Per Cent Response of Each Specialty Group of Nurses Indicating whether the Patient Would Benefit if the Nurses Were Medication Specialists . . . . . . . . . . . . 40

9. The Activity that Would Most Improve Pharmacy and Nursing Services, Per Cent Response Comparing University Graduates with Rest of Population . . . . . . . . . . . . . . .

10. The Activity that Would Most Improve Pharmacy and Nursing Services, Per Cent Response by Nursing Shift... . . . . . . . . . 44 
LIST OF TABLES--Continued

Table

11. Per Cent of Nurses on Each Shift Indicating How Often They Confer with a Pharmacist

for Drug Information. . . . . . . . . .

12. Per Cent of Nurses in Each Specialty Indicating How Often They Confer with a Pharmacist

for Drug Information. . . . . . . . . .

13. Specialty Nurses Who Differed from the Group As a Whole As They Selected Either "Pharmaceutical Calculations" or "Knowledge of Which Drugs Can Be Used Together" As Areas in Which They Felt Least Adequate . . . .

14. Per Cent of Nurses in Each Hospital and Level of Supervision Selecting the Service that Would Be Most Welcome . . . . . . . . . 


\section{ABSTRACT}

Hospital employees must do a great deal of spontaneous adjusting to accommodate each other and the patient. Interdependence must be accepted. Professionals must behave according to each other's expectations. The purpose of this study is to gain an overview of nurses' attitudes toward pharmacy services and to reach helpful conclusions. A preliminary survey conducted in a large hospital using open-ended questions is used to develop a multiple choice questionnaire. This second questionnaire is used in an expanded survey of nurses in five Arizona hospitals. The pharmacists in the test hospitals are asked similar questions to determine the extent of agreement between nurses and pharmacists. The results show statistically significant differences in answers between nurses of different (1) hospitals, (2) levels of supervision, (3) specialties, (4) levels of education, (5) years of experience, (6) shifts worked, and (7) years of tenure. Pharmacists and nurses are not in agreement on several subjects. Three groups of nurses are shown to especially need more contact with pharmacists who must become more patient-oriented in order to offer services that nurses need. Nearly all nurses welcome the pharmacist at the patient level. Recommendations are made to nurses, pharmacists, and administrators. 


\section{CHAPTER 1}

\section{INTRODUCTION}

The need and purpose of such a project is discussed and the working hypothesis is presented. The methodology of two surveys is explained.

\section{Need and Purpose}

The hospital is a complex and specialized problemsolving system. The primary goal and basic product of the system is to render high quality care and service to the patient. To this end, all other objectives are subordinate, though not necessarily unimportant.

Professionalism, specialization, and heterogeneity of functions make up the action structure of the hospital. People in the organization are of varying backgrounds. Because the people are in close contact and frequent interaction, sources and possibilities of friction are numerous. The impact of problems and errors can readily generalize throughout the entire system.

Work is interdependent. One's performance is often contingent upon the work of others. The nature of the work requires a well-working system of mutual understanding about one another's work. It is not enough that members comply with rules and regulations. Much depends upon spontaneous 
day-to-day adjustments that the organizational members are willing to make to accommodate each other and the patient. The different groups (pharmacists, nurses, physicians, technicians) must understand the work problems and needs of others. Much depends upon voluntary discipline and professional self-control. The specialists in the system must be willing to accept their interdependence and behave according to each other's expectations and requirements (Georgopoulos 1966, p. 8-16).

There is a strong relationship between similarity of beliefs, attitudes, and goals on the part of members of a group and group cohesiveness. In general, the more similar these attitudes, the better the relationships and the stronger the desire to belong to the group. This is especially true when the attitudes are related to the significant aspects of the interaction process. In the hospital, differences in attitudes in something as central as patient care can precipitate tensions. This can result in administrative problems and also endanger the patient (Zungolo 1968, p. 40$)$.

An attitude is a feeling. It can be described as a degree of positive or negative effect associated with some fsychological object. Attitudes cannot be considered without first examining the values of a person. Values are conceptions of what is important. Values involve choices and 
instigate behavior which can be judged according to the extent of desirability.

One must also consider the concept of role when dealing with attitudes. The role can be described as the cluster of special functions that come to be expected of a given class of workers within positions they typically occupy in the organizations or social systems in which they work. These expectations come from (I) official sources (administrators, governing bodies), (2) immediate colleagues,

(3) reference groups (professional groups, educators), and (4) the worker himself. Working relationships between medical specialists are influenced to some extent by the images they hold of each other. Stereotyping is found in all facets of group relationships. It is important how a person perceives his own group and other groups of which he is not a member. Idealization can be defined as a tendency to see another as like or different from a person's ideal image of him. Identification is the extent to which a person sees another as having similar characteristics. Esteem is the degree to which the desirable characteristics are attributed (Benne February 1959, p. 196; Zungolo 1968, p. 40).

There are demands from hospital administrators, nurses, government agencies, pharmacy educators, and professional pharmacy organizations for the pharmacist to become more involved at the patient level; to become more active outside the four walls of the pharmacy (Carlin 1966, p. 83; 
Brodie 1968, P. 1948-1951; "Pharmacists Realign Goals" 1968, p. 75-76). As the pharmacist responds to these demands, he will find himself in more contact with others from whom he has been previously insulated. The primary contact will be with the nurse. The nurse is generally the only person in the hospital who assures a continuity of action around the patient. As roles of pharmacists and nurses change, new conflicts will arise if one group assumes some traditional activities of the other. It will be to the patient's advantage if nurses and pharmacists try to understand each other's roles, self-expectations, and the expectations one group holds for the other.

It is the purpose of this study to gain an overview of attitudes some nurses have of pharmacy services and to reach some conclusions that may help pharmacists understand what is expected of them. This research will attempt to identify attitudes and needs of special groups of nurses.

\section{Working Hypothesis}

There are significant differences in attitudes among nurses in hospitals toward pharmacy services. These differences are characteristic of (1) level of supervision, (2) shift worked, (3) nursing specialty, (4) type of education, (5) number of years in present hospital, (6) number of years of experience, and (7) the hospital itself. 


\section{Methodology}

Preliminary Survey

A 450-bed teaching hospital was selected for a preliminary survey. The nursing service was organized by team method. The pharmacy had a 24-hour service and received direct copies of original physicians' orders from one surgical unit and one medical-surgical unit (see Hospital \#l under Description of Hospitals, Chapter 2). A list of registered nurses was obtained from nursing service. Each name was given an identifying number. This list of numbered names was returned to the Director of Nursing. Numbers were drawn at random with replacement until 100 registered nurses had been selected. A list of the selected numbers was given to the Director of Nursing and a copy retained by the researcher.

Questionnaires of 14 open-end questions (see Appendix A) were distributed by nursing supervisors to the test group. The completed questionnaires were returned directly to the researcher. This was done to insure anonymity. Each questionnaire carried its identifying number and was checked off the researcher's list as it was returned. After two weeks, a follow-up was conducted on the outstanding questionnaires. This was done by giving the outstanding numbers to the nursing supervisors who then reminded each nurse personally. Figure $I$ is a flowchart showing the procedure. 


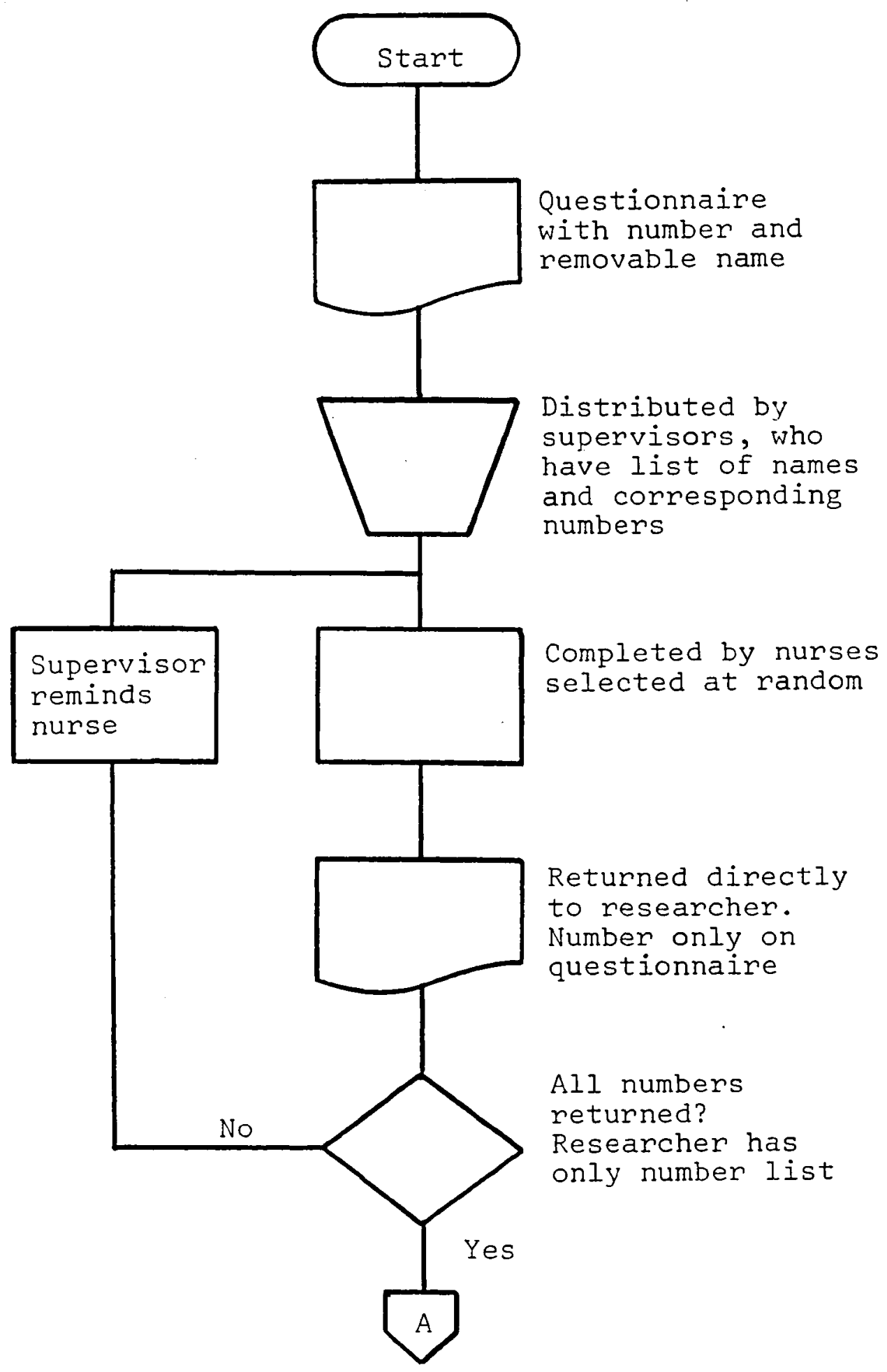

Figure 1. Flowchart Showing Procedure for Handling Preliminary Survey 


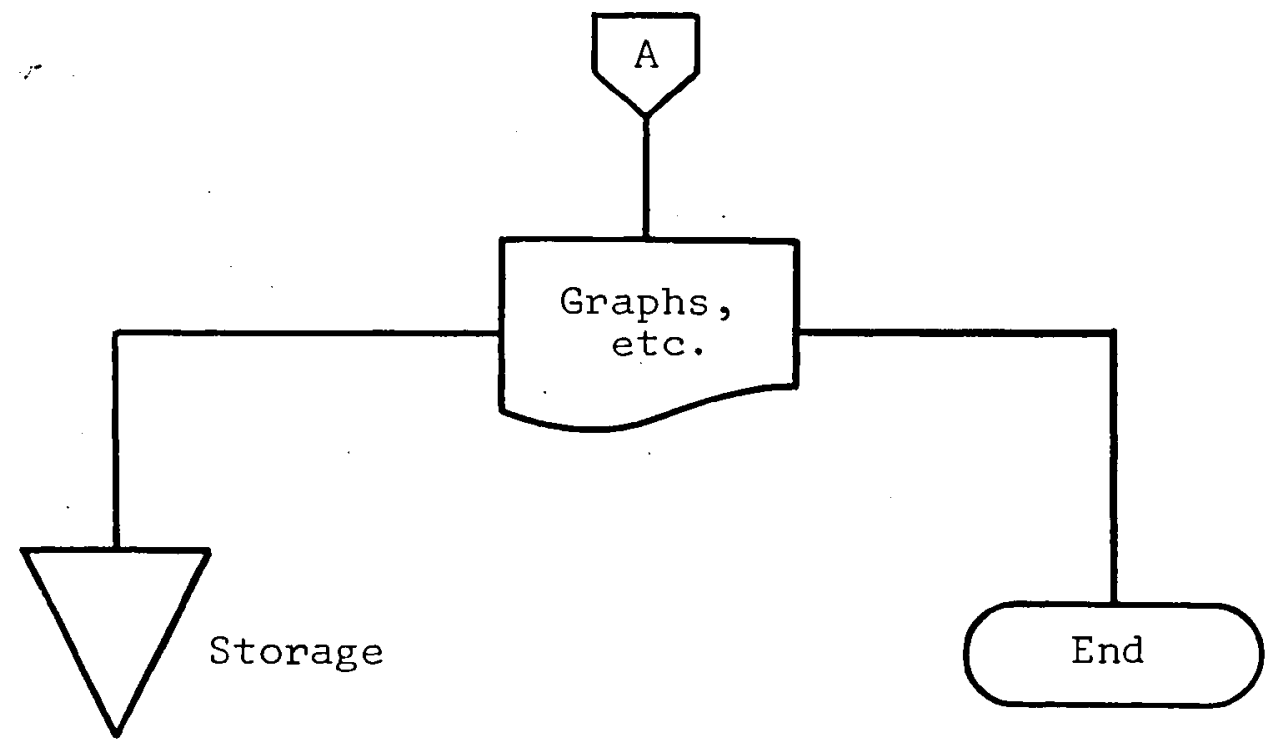

Figure 1. --Continued 
Eighty-one questionnaires were returned, of which seven were supervisors'. It was found that the questions were not applicable to the supervisors' situations, and this group was left out of the tabulation. The breakdown of nurses responding by groups is shown in Table 1. Analysis of these figures showed a proportional representation of the registered nurse population of the hospital for each group.

Results were tabulated and illustrated in bar graphs by per cent of each group giving the answer. The results suggested that each group in Table 1 might have its special problems, interests, and attitudes. It was decided to design a questionnaire of twenty multiple choice questions based on the answers given in the preliminary survey. The questionnaire was to be used in an expanded survey involving more nurses in other Arizona hospitals.

Final Survey

Five hospitals were selected for the survey. Two hospitals were representative of hospitals in the 100-200bed capacity class; one was in the 200-275-bed class; one was in the 275-350-bed class; and the largest was in the 400-500-bed class. Four of the hospitals were in Tucson and one was in Phoenix (see Chapter 2 for descriptions). Questionnaires with self-addressed, stamped envelopes were distributed to all nurses in each hospital (see Appendix B). 
Table 1

Numbers of Nurses Responding to Surveys

by Groups

Group

$\underline{\text { Preliminary Survey }}$ Final Survey

Level of supervision:

Supervisors

Head Nurses

Assistant Head Nurses

Team Leaders

Preliminary Survey Final Survey

t:

$7-3$

$3-11$

$11-7$

40

-Not included-

13

13

68

48

51

255

Shift

20

14

183

111

80

Unit:

Medical

23

77

Surgical

OB-GYN

Labor and Delivery

21

55

5

15

Emergency Room

11

Pediatrics

26

Nursery

Float

Intensive Care

3

3

28

7

16

4

49

6

97

Education:

University Degree

No University Degree

Years in Nursing:

Less than 5

$5-10$

19

78

II-20

16

96

More than 20

18

118

Years in this Hospital:

Less than 1

$1-10$

47

95

10 or more

11

Total Nurses Responding

74 
Follow-up on the outstanding questionnaires was accomplished after two weeks by sending a letter to each director of nursing.

The results were prepared for tabulation by placing values on coding sheets as they were to appear on the data cards. The coding sheets were visually verified (see Appendix C). Columns 1-7 represented a description of the nurse as answered in questions $A-G$ of the questionnaire. Columns 20-39 were reserved for answers to questions 1-20. If answer \#2 was selected by the nurse in response to question \#1, a 2 was placed in column 20; if answer \#1 was selected in response to question \#2, a 1 was placed in column 21 ; etc. A figure 7 in columns 20-39 indicated that the answer could not be tabulated because (1) no answer was checked, or (2) more than one answer was checked.

The data were punched into Hollerith cards (see Appendix D). Each card contained the information for one nurse. A listing was obtained and the data verified visually. Fortran programs were written for the CDC 6400 to compute (1) gross results by group and answer, (2) results for each hospital by group and answer, and (3) analysis of the population characteristics. See Figure 2 for the systems fiowchart and Appendix E for a sample output. The analysis of results also included an interview with the director of nursing and the director of pharmacy at each hospital studied. 


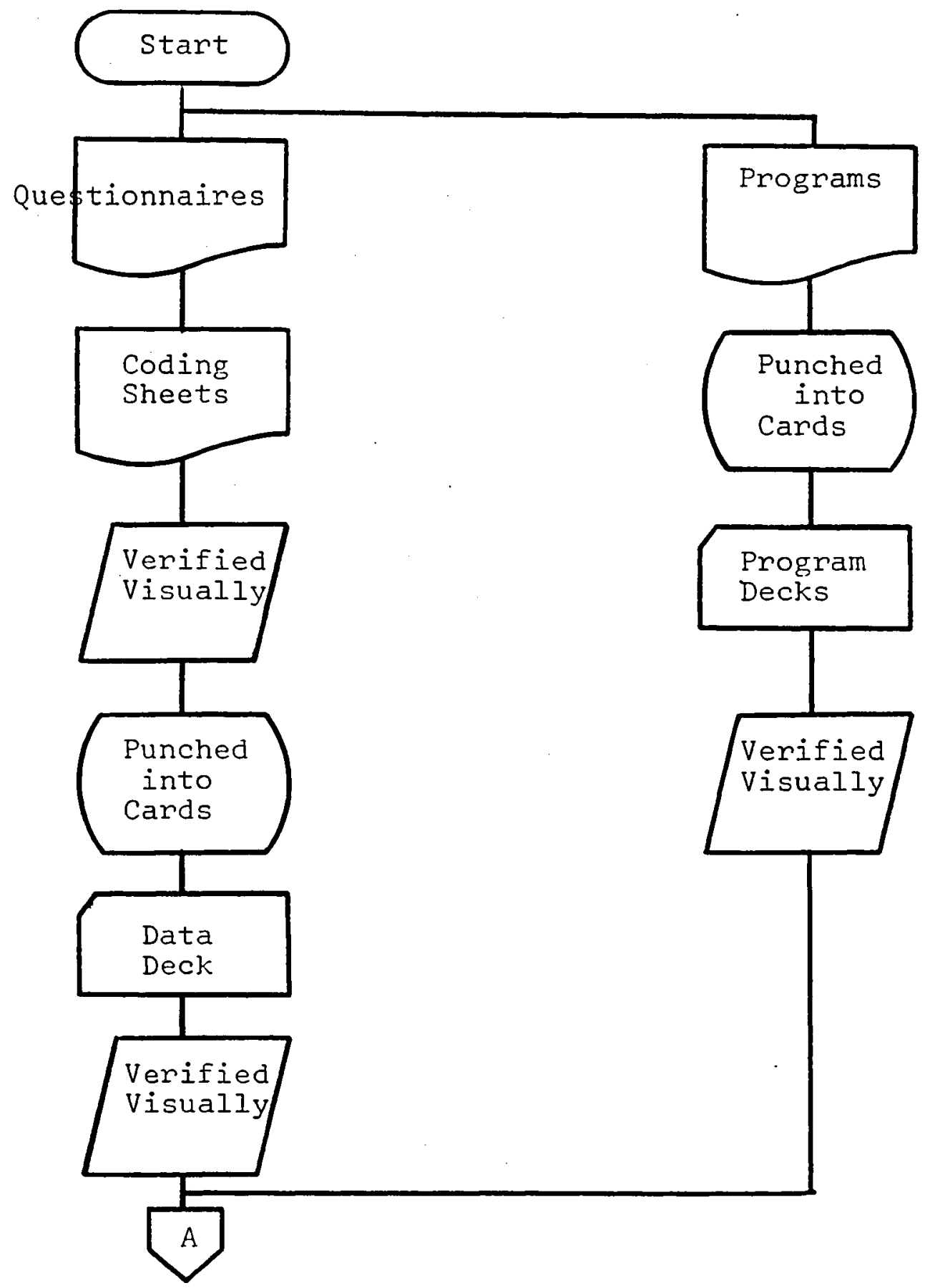

Figure 2. Systems Flowchart for Handling Data on Final Survey 


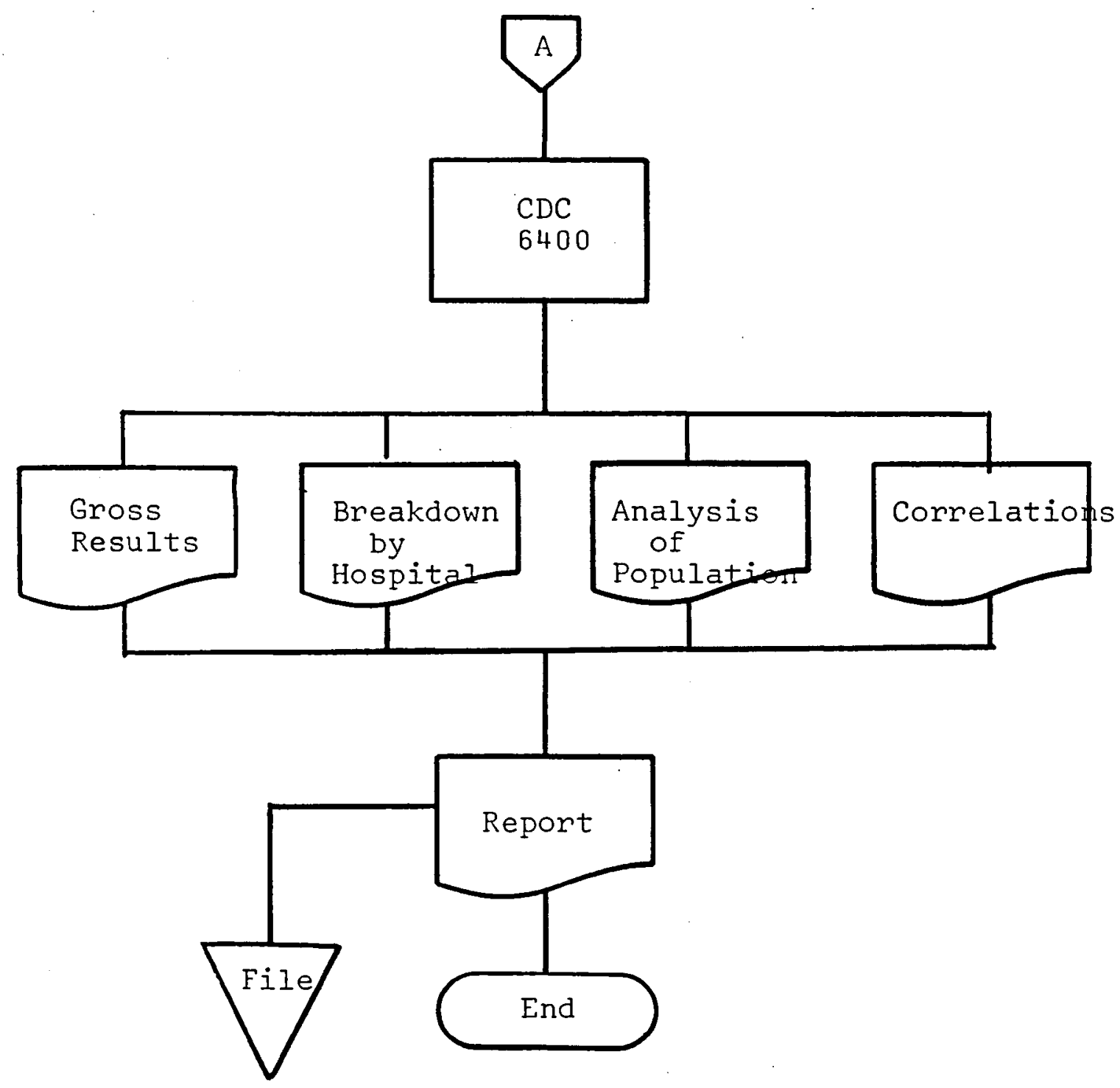

Figure 2. --Continued 
Similar questionnaires were distributed to the pharmacists in each hospital. The intent of this procedure was to determine whether or not nurses and pharmacists were in agreement. Of the 22 questionnaires distributed to pharmacists, 72.7 per cent were returned. See Appendix F for a sample questionnaire.

Table 1 shows the numbers of nurses responding to the final survey by groups. Table 2 shows the number of nurses that responded from each hospital. Of the 500 questionnaires distributed to nurses, 74.8 per cent were returned.

Table 2

Numbers of Nurses Responding to Final Questionnaire from Each Hospital

\begin{tabular}{cc}
\hline \hline Hospital & Number \\
\cline { 2 - 2 }$\# 1$ & 147 \\
$\# 2$ & 20 \\
$\# 3$ & 39 \\
$\# 4$ & 98 \\
$\# 5$ & $\frac{70}{374}$ \\
Total & \\
\hline
\end{tabular}


CHAPTER 2

\section{DISCUSSION}

Brief descriptions of the hospitals that were surveyed and results of the preliminary and final surveys are presented. The correlation and significance tests that were employed are explained.

\section{Description of Hospitals}

Hospital (I) was a non-government, not for profit, short-term teaching hospital with about 450 beds. The average census was 83 per cent of capacity. The pharmacy service was available 24 hours per day, seven days per week. The Pharmacy was staffed with four staff pharmacists and a supervisor on the day shift, two pharmacists on the evening shift, and one pharmacist on the night shift. Pharmacy students were used on evenings and weekends.

Hospital (2) was an osteopathic, not for profit, short-term hospital with about 140 beds. Occupancy averaged 83 per cent of capacity. The pharmacy service was offered about 100 hours per week with night service (after ll p.m.) supplied by an on-call pharmacist. Staffing the day and evening shifts was accomplished by (1) two staff pharmacists and a supervisor on days, and (2) a staff pharmacist on evenings. Pharmacy students were utilized evenings and weekends. 
Hospital (3) was a not for profit, short-term, nongovernment hospital of 140 beds. The average census was 62 per cent of capacity. The pharmacy service was available about 90 hours per week with daytime and evening hours most often staffed by one pharmacist per shift. The night hours (after 10 p.m.) were covered by a pharmacist on call. Hospital (4) was a non-government, not for profit, short-term hospital of 240 beds. The average census was 87 per cent of capacity. The pharmacy service was offered 105 hours per week. Staffing was accomplished with three daytime pharmacists and one evening pharmacist. Pharmacy students were utilized throughout the day and evening. Needs after Il p.m. were usually met by the night nursing supervisor. Hospital (5) was a non-government, not for profit, short-term hospital of nearly 300 beds. The average census was about 76 per cent of capacity. Pharmacy service was available 105 hours per week. Two daytime pharmacists and a supervisor and one evening pharmacist were employed. Pharmacy students were utilized on both shifts. Night services (after 11 p.m.) were handled by an on-call pharmacist. In all of the hospitals, the pharmacy services were central with the pharmacists venturing very little from the confines of the pharmacies. One exception was the pharmacist who worked the night shift in Hospital (1). That pharmacist spent a bulk of the hours being present on the nursing units 
and participated in medical emergencies. Pharmacy service was available in all hospitals seven days per week.

\section{Findings of Preliminary Nurse Survey}

Question A: What is the general goal of your department?

The answers to this question were too general and could not be tabulated. Typical statements were: (1) "Total patient care," (2) "Complete patient care," and (3) "Best patient care." The response to this question suggested that the nurses had no one outstanding way to describe the goal. Nearly all statements mentioned the patient.

Question B: What duties do you now perform which you feel are unrelated to duties as a nurse?

There were 32 different duties reported from administering medications to collecting money for baby pictures. There seemed to be a correlation between the frequency of saying "nothing" and the amount of direct patient care. Nurses who spent more time in actual contact with patients tended to say they did not do anything that was unrelated to their roles.

The supervisors were asked to rank the shifts and administrative levels according to amount of direct patient contact. They ranked head nurses as having the least amount and team leaders as having the greatest amount of patient contact. They also ranked the $7-3$ shift as providing the least opportunity for direct patient contact and the 11-7 
shift as providing the most. The distinction between shifts was not as great as between administrative levels.

Role satisfaction, which was indicated by the number of unrelated duties reported, was related to the amount of direct patient contact. Surgical nurses seemed to have the most role satisfaction. This may have been due to a phenomenon reported in a study by Lancaster (1967) which suggested that surgical nurses had less need for relationship with their patients than did medical nurses.

There also seemed to be an inverse relationship between the number of years in nursing and the tendency to list duties as being unrelated to the role. Initial dissatisfaction or role deprivation was described by Kramer (1968); Benne (1959); and Corwin, Taves, and Haas (1961). They found discrepancies in what the nurse expected and what she found upon leaving training and entering her first job. If her role conception did not change, she usually left for other areas of endeavor.

Paperwork was the most frequently reported duty. Staffing patterns may have affected these results. The 3-1l shift handled most of the admissions, but there were more clerks on duty during the 7-3 shift. This caused the nurses on the 3-1l shift to assume more clerical functions. They had a higher incidence of reporting paperwork. The frequency of this answer dropped as the nurses became older and had more experience in the hospital. This was an indication 
that the nurses were changing their role perceptions to conform with the expectations of the hospital.

Question C: What should you be doing instead?

The most frequent answer to this question was "bedside patient care." This answer was consistent among all groups. Nurses on the 3-1l shift, Intensive Care nurses, and nurses with eleven to twenty years of experience attached the greatest value to this aspect of nursing. Head nurses and university graduates wanted more time for teaching and supervision, meetings to discuss problems, and making rounds with physicians.

Question D: What services are provided by pharmacy that you feel are helpful?

The answers seemed to indicate that there was a generally high desire for information to be supplied by the pharmacy. When this information was provided, it was felt to be helpful. Mixing intravenous solutions and other technical services were of secondary importance.

Surgical nurses did not seem to appreciate the pharmacy calling about unusual dosages. Perhaps the surgical nurses felt that surgeons should not be questioned.

Question E: What services could pharmacy perform to help increase the quality of nursing care? 
There was a considerable delay from the time the medication order was written until the drug reached the patient. The answers reflected this problem and predominated over other needs. However, the requests for more information were numerous. Even though the information services were highly valued, delivery of medication to the patient took priority.

Question F: What services could pharmacy perform to help expand your therapeutic service to both patient and family? There were 29 different answers to this question. One-third of the nurses did not answer. Because the question cut across traditional lines of thought, it may have caused confusion. This might have indicated that nurses did not think in terms of role expansion or that it was a poorly worded question.

Ten answers were direct invitations for more pharmacist involvement with the nurse, physician, patient, and patient's family. The balance of the answers were concerned with more mechanical help; i.e., faster filling of orders and expansion of floor stock. The request for information was significant.

Question G: What services could nursing perform to help improve pharmacy service?

This question also seemed difficult to answer. One nurse wrote: "I have always thought that it was pharmacy 
that was supposed to help nursing." The majority of answers reflected the system used in ordering drugs. A clerk wrote the order from the chart and a nurse signed it after checking. Many slips arrived at the pharmacy with obvious errors which had to be corrected. Most nurses thought they could do a better job of checking.

The second most frequent answer was "Anticipate need--send orders promptly." Twice as many surgical nurses as medical nurses indicated this. There may be greater emphasis on patient care planning on surgical floors, since the progress of the surgical patient is more defined than that of a medical patient. Medication therapy was almost predetermined. On a medical floor, there were more medications given with varying dosages and more "stats" and discontinued medications. The intensive care unit nurses mentioned this answer frequently. The intensive care unit was a highly organized unit with much interdependence among the personnel. Delays and shortages would have a greater effect on the patient in intensive care.

Question $\mathrm{H}$ : What do you feel you need to know about drugs? The priorities in descending order were (I) side effects and toxicity, (2) indications for use, (3) normal or desired effects, and (4) pharmacological action. In general, more surgical nurses felt they needed knowledge than did medical nurses. Medical nurses mentioned "pharmacological 
action" more than "desired effects." The answers may have given hints as to the type of information desired by each group. Even though "pharmacological action" was last, a better background in this area might have eliminated the problems of lack of information in the first three areas.

Question I: What do you feel are the qualities of an effective pharmacist?

There were a total of 30 different answers given. Nurses mentioned "works well with others," "knowledge of drugs," "accuracy," and "courteous" in order of decreasing frequency. Medical nurses tended to spread their feelings among the other 26 answers. As the nurses worked more with patients, they valued a pharmacist with a good knowledge of drugs. Nurses who had more technical help (aids, orderlies) tended to prize a pharmacist who was cooperative and worked well with others.

Question J: Can you usually identify the reasons for problems that arise between you and pharmacy? Please give examples.

Most answers suggested problems arose from the mechanics of ordering and drug distribution. A few answers were of the humanistic variety and suggested poor communication and lack of understanding. Surgical nurses tended to emphasize the mechanical aspects. Medical nurses emphasized 
the humanistic aspects to a greater extent. The 3-II and 11-7 shifts reported "no problems" most frequently.

Question K: What tools or techniques have you devised to improve relations with pharmacy?

There were 27 different answers. Nearly one-third of the population said "none" or gave no answer. These nurses were mostly assistant head nurses and older nurses. Team leaders, surgical nurses, and new employees mentioned politeness, pleasantness, courtesy, and consideration more than the average.

Question L: Is the pharmacy able to recognize your problems? Please give examples.

Most of the nurses felt that the pharmacy was able to recognize their problems. The head nurses were divided equally between "yes," "no," and "do not know." There seemed to be a correlation between the answers to this question and the answers to Question J. As the incidence of "no problems" increased, the incidence of "yes" increased among most groups. This suggested that problems may be minimized if pharmacists are perceived by nurses to recognize the problems of nursing.

Question M: What standard practices have you devised to avoid problems in handling drugs? 
There were 36 different answers to this question. About 20 per cent of the nurses said they check with pharmacy. This compared with 44 per cent who used other sources, such as the Physicians' Desk Reference, package literature, or other nurses as references. Pharmacy was not the first choice for advice.

Question N: How can the pharmacist become more knowledgeable of the forces involved in nursing care which tend to influence your work?

About 75 per cent of the answers suggested that the pharmacist become more involved in patient care. Interdepartmental meetings were mentioned. Only two nurses felt that the pharmacists could not gain knowledge in this area. Most of the answers were direct invitations to participate.

\section{Final Survey}

Significance and Correlation Studies

Each question was analyzed using $\mathrm{Chi}^{2}$ to see if there was any relationship between the way it was answered and the categories of (1) hospital, (2) level of supervision, (3) shift worked, (4) specialty, (5) experience, (6) level of education, or (7) tenure. A significance level of 0.1 was selected to detect differences between groups. A contingency coefficient of correlation was calculated for the significant results to give evidence of strength of relationship. 
Results

Question (1). This question asked if the information supplied by pharmacy was adequate or inadequate. There seemed to be no significant relationships between the categories of nurses and the way the question was answered. Over 86 per cent of the nurses said they thought the information was adequate.

Hospital (1), with 24-hour pharmacy service, exhibited a higher percentage of nurses on the 11-7 shift who said the information was adequate than the 11-7 nurses in the rest of the population (Figure 3 ).

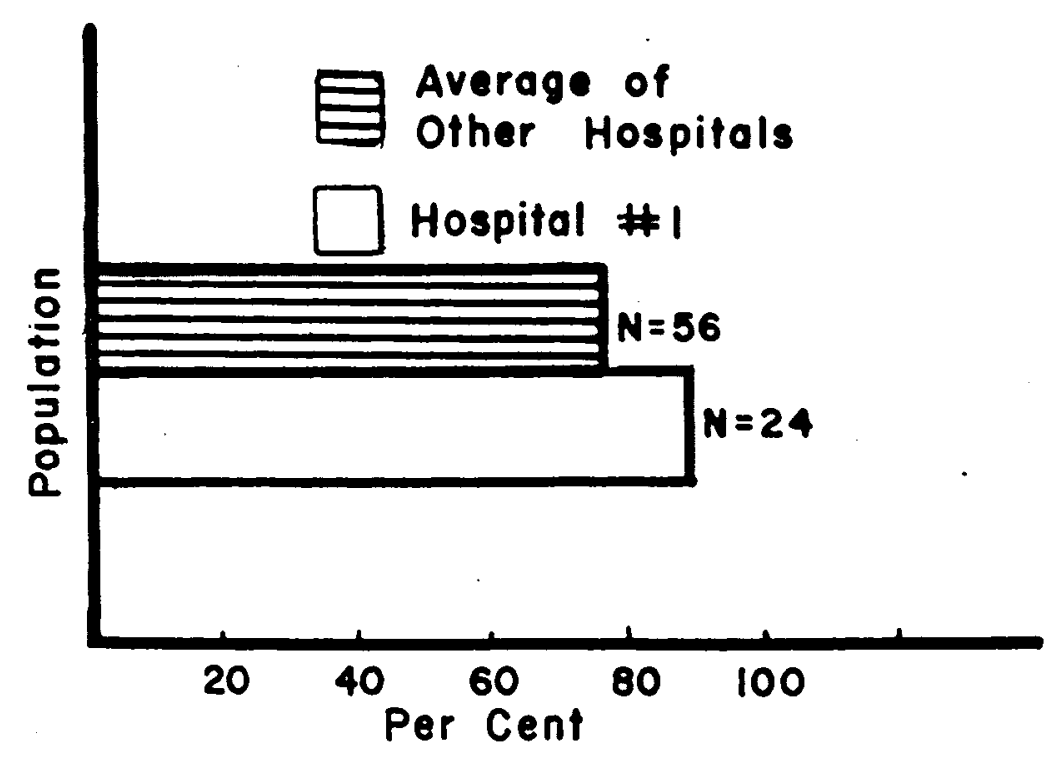

Figure 3. Nurses on the 11-7 Shift Reporting Adequate Information from Pharmacy. Hospital (I) Compared to Others. 
Figure 4 shows that fewer nurses on the 7-3 shift in Hospital (1) rated the pharmacy information as being adequate than did the 7-3 nurses in the rest of the hospitals. In Hospital (I) the pharmacists were extremely busy with technical duties leaving little time for them to do literature searching or on-the-scene consulting with nurses. Ten of the 16 pharmacists who responded felt the information they supplied was inadequate.

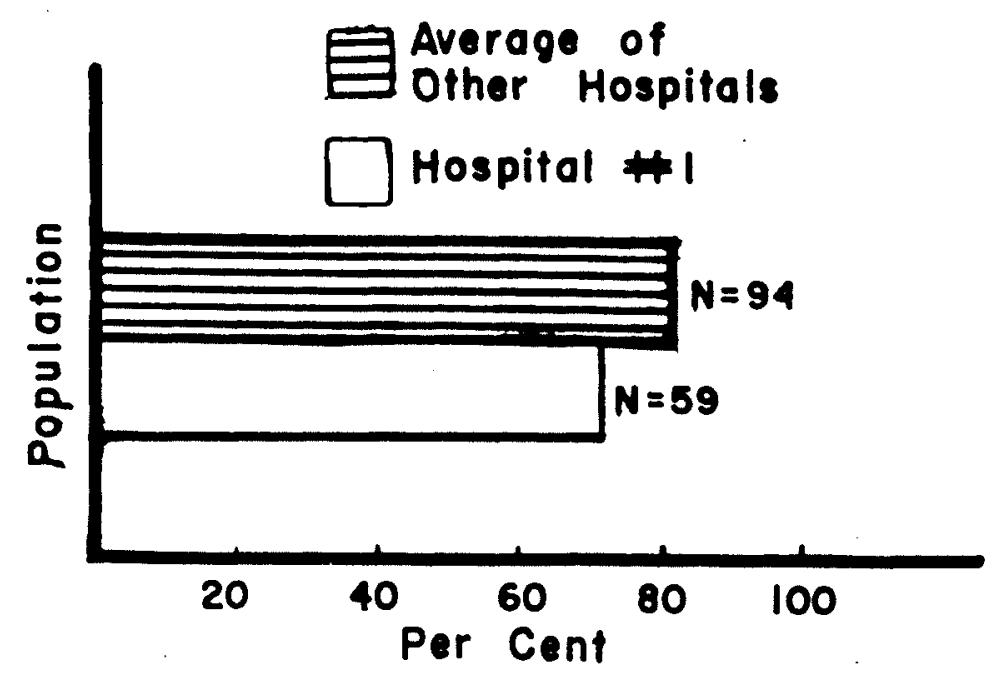

Figure 4. Nurses on the 7-3 Shift Reporting Adequate Information from Pharmacy. Hospital (I) Compared to Others. 
Question (2). This question asked the nurses to choose which source of information was the best. The Physicians' Desk Reference was named by 66 per cent of the nurses. This popularity was very consistent between categories of nurses. Package information and pharmacy ranked second and third with 13 per cent each, and the formulary ranked fourth. Hospital (4) was the only hospital using a formulary (one supplied by the American Society of Hospital Pharmacists), and 10 per cent of the nurses in that hospital chose it as the best source. However, three nurses in Hospital (3) and one nurse in Hospital (1) chose the formulary. This may have indicated previous satisfaction.

The two smallest hospitals, (2) and (3), accounted for the poorest showing by pharmacy. Hospital (2) nurses chose the Physicians' Desk Reference more frequently. Chapter 2, Description of Hospitals, shows that the two smallest hospitals provided pharmacy service the fewest number of hours per week. Figure 5 shows the results by hospital and answer.

Nurses in the groups with greatest experience tended to recognize pharmacy as the best source of information. This same trend took place for the choice of Physicians' Desk Reference. Nurses who had worked in the hospital for less than one year were much less inclined to choose the pharmacy than were nurses who had 10 or more years of experience. 


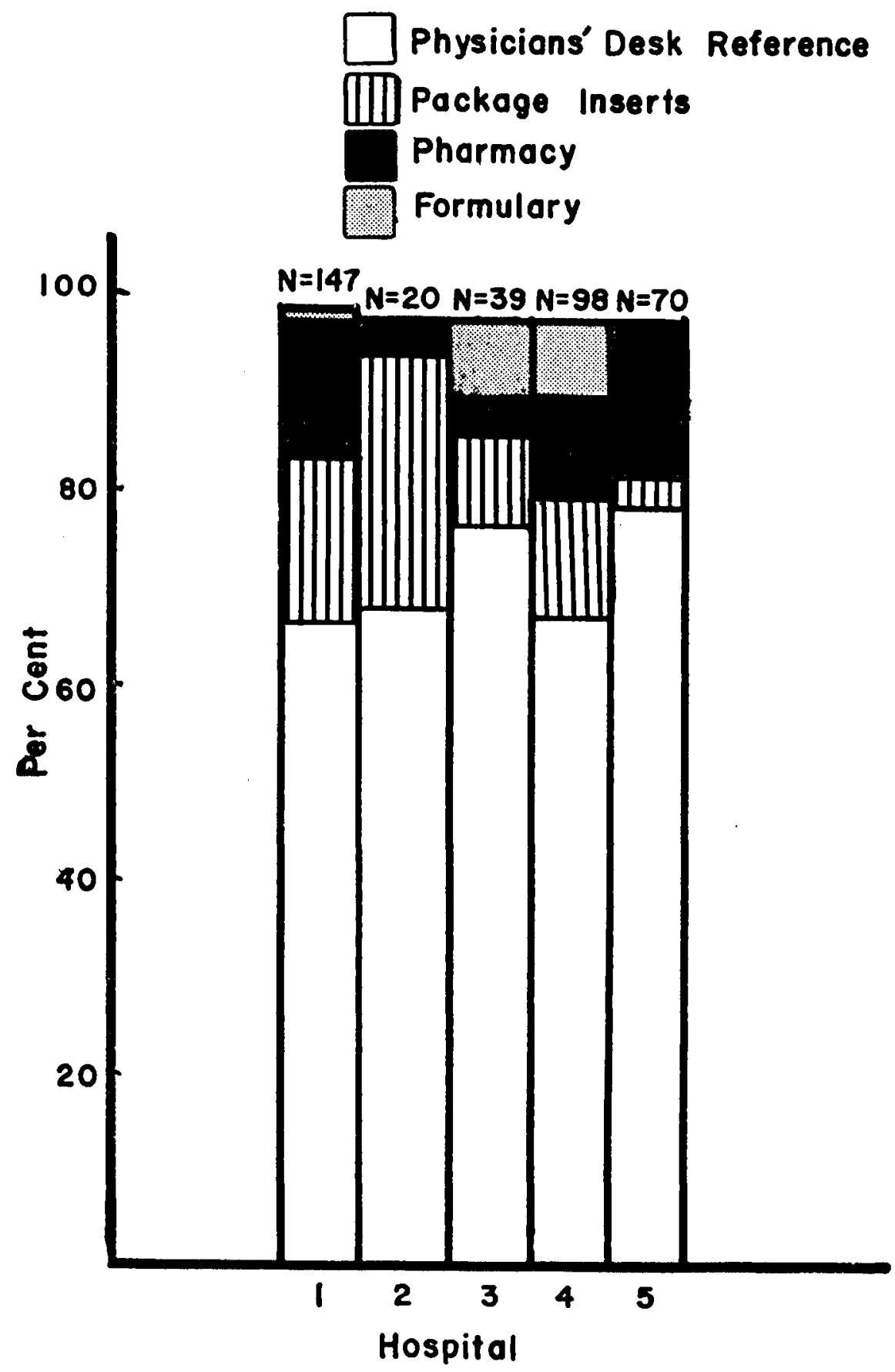

Figure 5. Per Cent of Nurses in Each Hospital Choosing Best Source of Information 
Figures 6 and 7 illustrate the popularity of the pharmacy as related to years of experience and tenure.

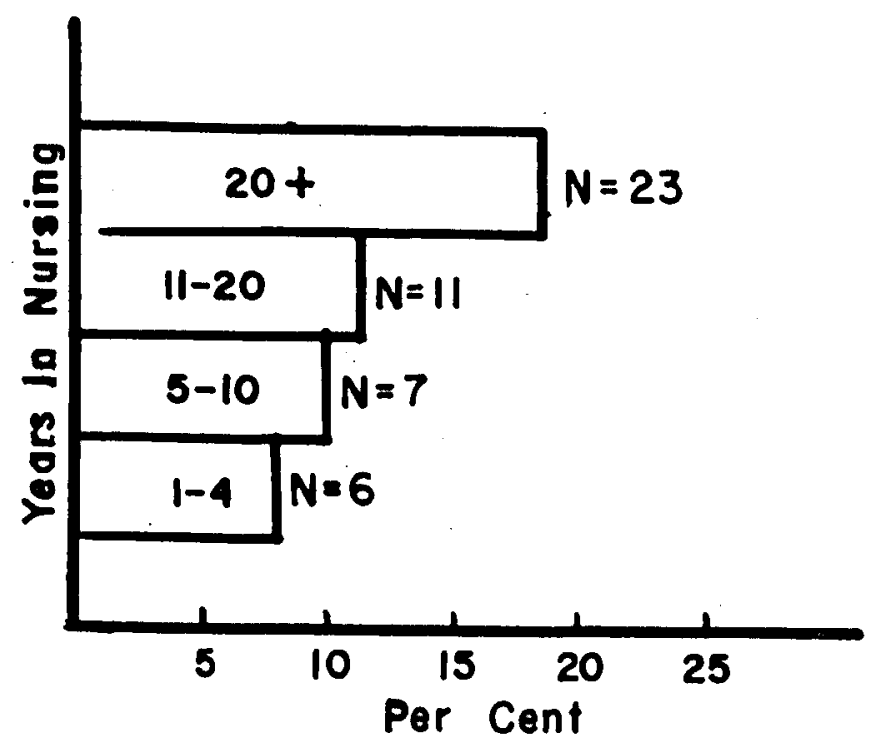

Figure 6. Per Cent of Nurses in Each Experience Group Choosing Pharmacy As the Best Source of Information

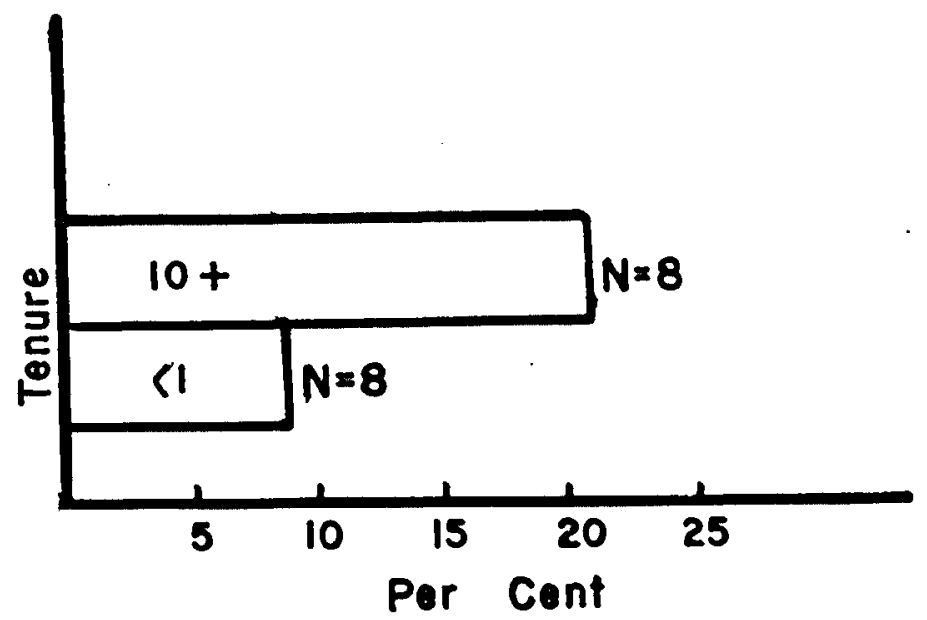

Figure 7. Per Cent of Nurses in Each Tenure Group Selecting Pharmacy As the Best Source of Information 
Seven of the 16 pharmacists chose the pharmacy as the best source of information. Five chose the hospital formulary, and the rest chose the Physicians' Desk Reference.

A significant result showed medical nurses (Figure 8) giving a high degree of preference to the pharmacy with a corresponding low preference to the Physicians' Desk Reference, as shown in Figure 9. University graduates followed the same trend at a significance level of 0.01 . The university graduates showed a high degree of preference for the formulary. The actual frequency response of university graduates choosing the formulary was over two-and-one-half times the expected frequency.

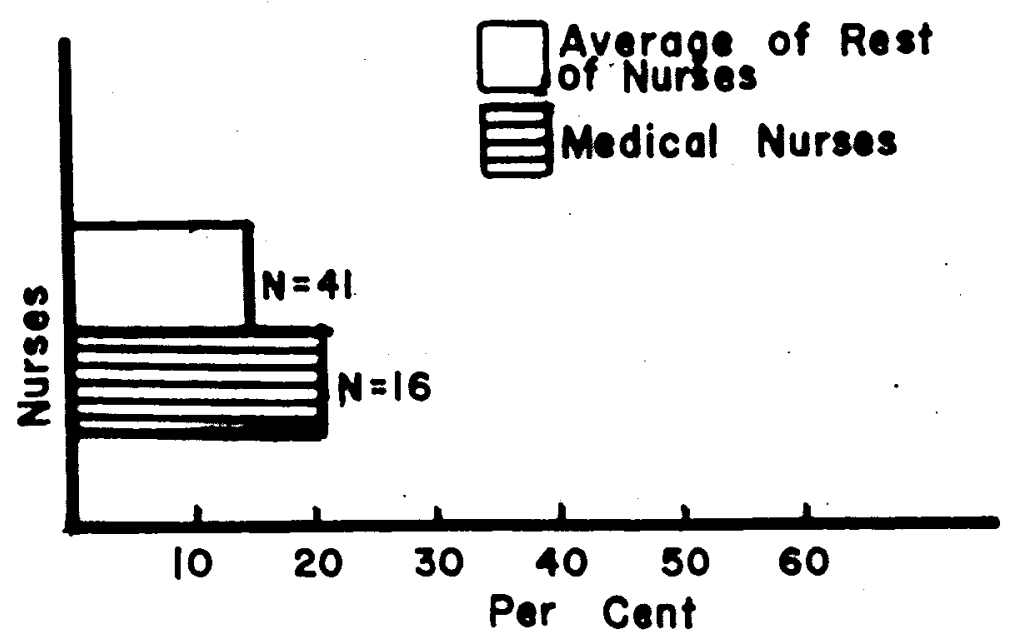

Figure 8. Per Cent of Nurses Saying Pharmacy Is the Best Source of Information, Comparing Medical Nurses to the Rest of the Population 


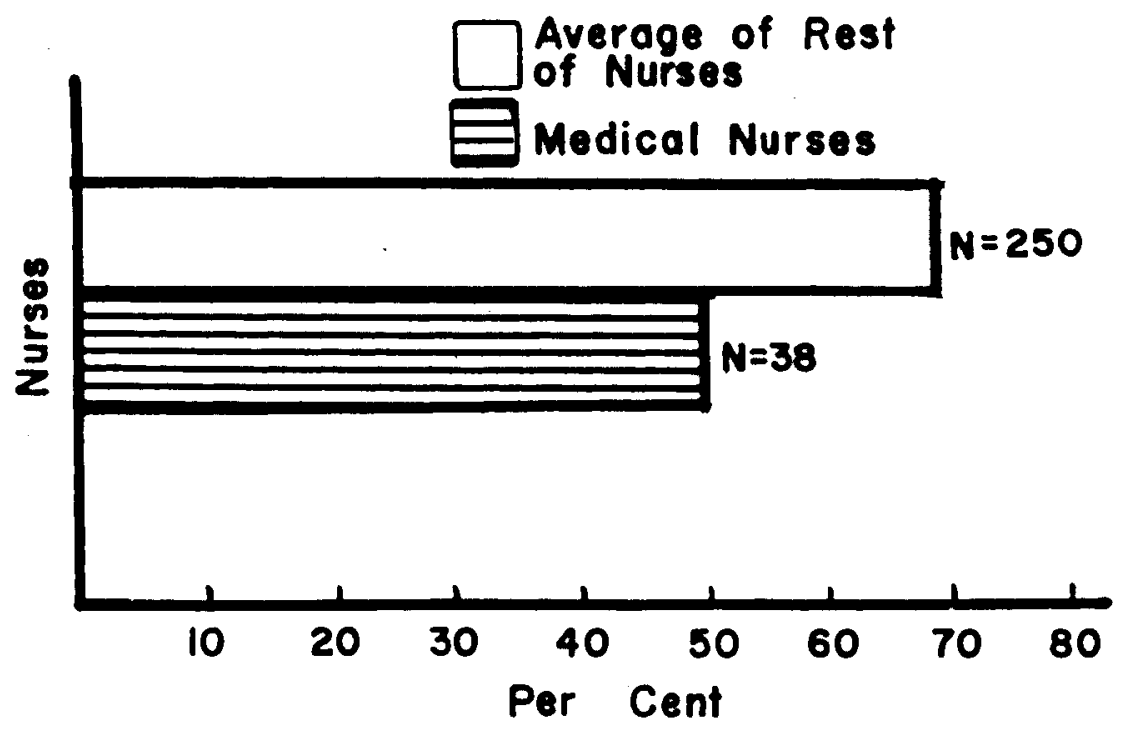

Figure 9. Per Cent of Nurses Saying Physicians' Desk Reference Is the Best Source of Information, Comparing Medical Nurses to the Rest of the Population 
Question (3). The nurses were asked to select the most appropriate perception of the pharmacy service. The per cent response for each answer is shown in Table 3 . There were no significant patterns of answers characteristic of categories of nurses. Fourteen pharmacists felt they were usually helpful when called. The other two felt they were usually helpful but bothered by questions.

Table 3

The Extent to Which Nurses Feel the Pharmacy

Is Helpful and/or Bothered When Called

Pharmacy when called is:

Response

1. Usually helpful

2. Usually helpful, but bothered

3. Usually not helpful

4. Usually not helpful, and bothered

5. Unable to tabulate
Per Cent

89.3

7.4

0

0

$3: 3$

Question (4). This question asked the nurses to indicate what time would be best to have a visit at the nursing unit by a pharmacist. The hospitals, the shifts, and the specialties all affected the answers significantly. The overall results are shown in Table 4. The answer of prima'y interest in this paper was \#4: "No need to talk to a 
pharmacist." It was desired to clearly demonstrate that some nurses actually felt that there was no need to have personal contact with pharmacists in the course of performing their duties.

\section{Table 4}

Per Cent Responses from Nurses on All Shifts to Desirable Time During Shift for Pharmacist to Visit Nursing Unit

\begin{tabular}{|c|c|c|}
\hline & Response & Per Cent \\
\hline 1. & Early & 17 \\
\hline 2 . & Late & 12 \\
\hline 3. & Middle hours & 56 \\
\hline 4 . & $\begin{array}{l}\text { No need to talk to } \\
\text { a pharmacist }\end{array}$ & 10 \\
\hline 5 . & Not able to tabulate & 5 \\
\hline
\end{tabular}

The answer, "No need to talk to a pharmacist," was given with about the same frequency percentagewise for each hospital. As shown in Figure 10, nurses categorized by shifts had different perceptions of their dependence upon pharmacy. The 11-7 nurses in Hospital (1) responded quite differently than the 11-7 nurses in the rest of the hospitals $\left(p^{<.1)}\right.$, as shown in Figure 11 .

In all five hospitals, the number of pharmacists available decreased as the workday progressed from the 7-3 through the 11-7 shifts. The specialties which tended to 


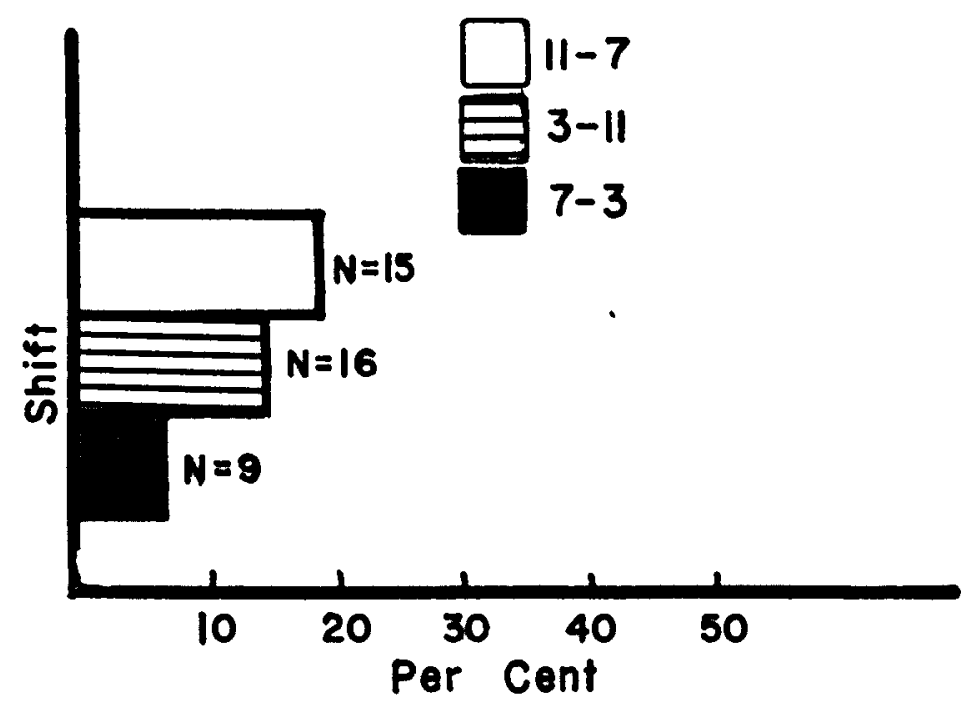

Figure 10. Per Cent Nurses on Each Shift Reporting No Need to Talk to a Pharmacist

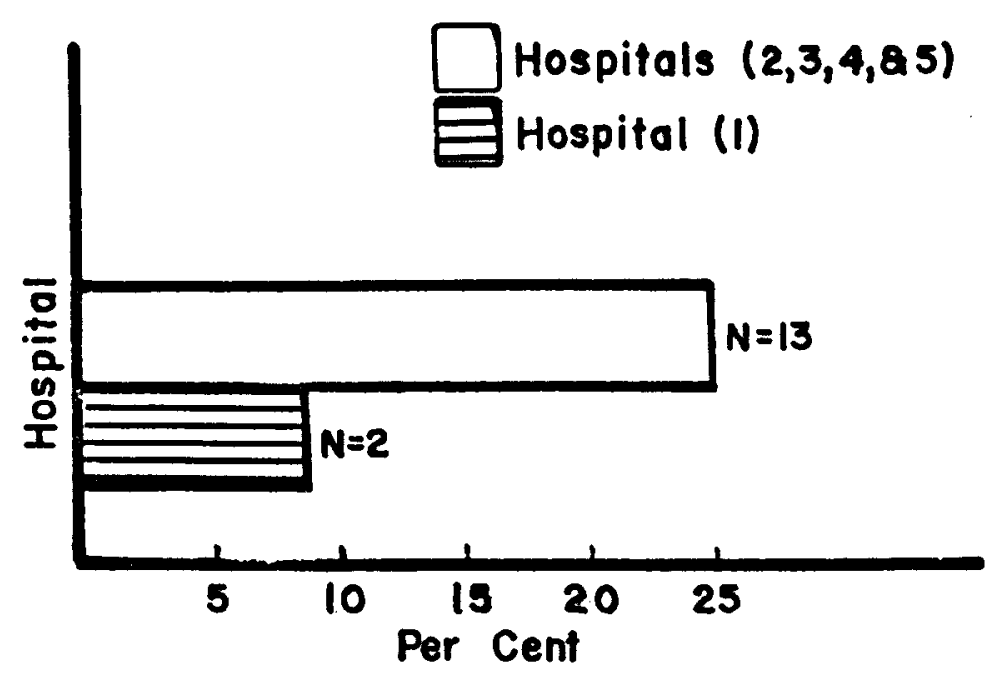

Figure 11. Per Cent Nurses on the 11-7 Shifts Reporting No Need to Talk to a Pharmacist, Hospital (1) Compared with Combined Results of Other Hospitals 
choose "No need to talk to a pharmacist" frequently were ones which used fewer drugs; such as, labor and delivery, emergency room, and nursery. Only two pharmacists felt nurses had no need to talk to pharmacists.

Question (5). The nurses were requested to indicate whether or not they felt they could ever learn all they should know about the medications they administer. The question was answered in such a way that the results were significantly affected by specialties $(\mathrm{p}<.01)$. Table 5 shows the results by specialty. Overall results are shown in Figure 12.

\section{Table 5}

Per Cent Responses of Nurses by Specialties Indicating if They Could Ever Learn All They Should know about the Medications They Administer

\begin{tabular}{lccc}
\hline Specialty & \multicolumn{3}{c}{ Answer } \\
\cline { 2 - 4 } & $\frac{\text { No }}{0}$ & $\frac{\text { Yes }}{0}$ & $\frac{\text { Unable to }}{0}$ \\
Medical & 53 & 47 & 0 \\
Surgical & 71 & 29 & 0 \\
Obstetrical/Gyn. & 33 & 60 & 7 \\
Delivery & 27 & 73 & 0 \\
Emergency Room & 42 & 58 & 0 \\
Pediatrics & 57 & 39 & 4 \\
Nursery & 38 & 62 & 0 \\
Eloat & 41 & 55 & 4 \\
Intensive Care & 68 & 31 & 1 \\
\hline
\end{tabular}




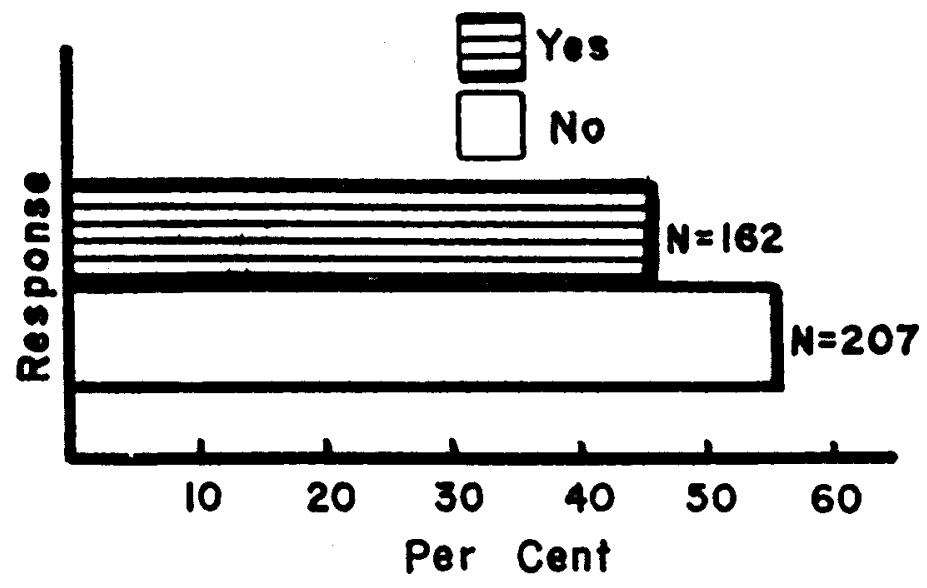

Figure 12. Per Cent Response of All Nurses Indicating if They Could Ever Learn All They Should Know about the Medications They Administer 
Some specialties were grouped as in Table 6 according to the relative emphasis in their work on medications and treatments, and the $\mathrm{Chi}^{2}$ test of significance was applied.

\section{Table 6}

Numbers of Nurses Grouped by Relative Emphasis in Work Indicating if They Could Ever Learn All They Should Know about the Drugs They Administer

\begin{tabular}{|c|c|c|}
\hline \multirow[b]{2}{*}{ Groups } & \multicolumn{2}{|c|}{$\mathrm{N}=$} \\
\hline & No. & Yes \\
\hline $\begin{array}{l}\text { Large variety of drugs, } \\
\text { few treatments. } \\
\text { (Medical nurses) }\end{array}$ & 41 & 36 \\
\hline $\begin{array}{l}\text { Less variety of drugs, } \\
\text { many treatments. } \\
\text { (Surgical nurses) }\end{array}$ & 39 & 16 \\
\hline $\begin{array}{l}\text { Small variety of drugs, } \\
\text { routine treatments. } \\
\text { (Nursery, Delivery, Emergency } \\
\text { room, and Obstetrical/Gynecological } \\
\text { nurses) }\end{array}$ & 25 & 42 \\
\hline $\begin{array}{l}\text { Large variety of drugs, } \\
\text { many treatments. } \\
\text { (Intensive care nurses) }\end{array}$ & 66 & 30 \\
\hline $\operatorname{chi}^{2}=20.71$ & & \\
\hline
\end{tabular}

Float nurses were not included, because the emphasis in their work was not known. The contingency coefficient of correlation was calculated to be .256, which showed a fairly high degree of relationship between the emphasis in the work 
situation and the answers obtained. It appeared from superficial examination of the data, that the answers were contingent upon the variety of drugs encountered and were independent of emphasis on treatments. Thirteen of the pharmacists felt that nurses could never learn all they should know about the medications they administer to their patients.

Question (6). Nurses were asked to indicate if they felt the patient would benefit if they were strictly medication nurses. Nurses classified by hospital varied significantly $(p<.01)$ in their answers. The answers also varied significantly at the .05 level according to specialty and experience. Education was significant at the .01 level; however, correlation studies showed little strength of correlation between answers and education. The answers were affected more by hospital than by any other group $(C=.22)$. Figure 13 shows how the nurses in each hospital answered the question

Medical nurses were most consistent between hospitals. Where the other nurses tended to drop in frequency of selection of the affirmative in Hospitals (1) and (4), medical nurses were very consistent. The frequency of medical nurses saying "yes" dropped, but still remained above average in these hospitals (Figure 14).

Intensive care nurses were strongly influenced in answering by unknown factors (possibly administrative 


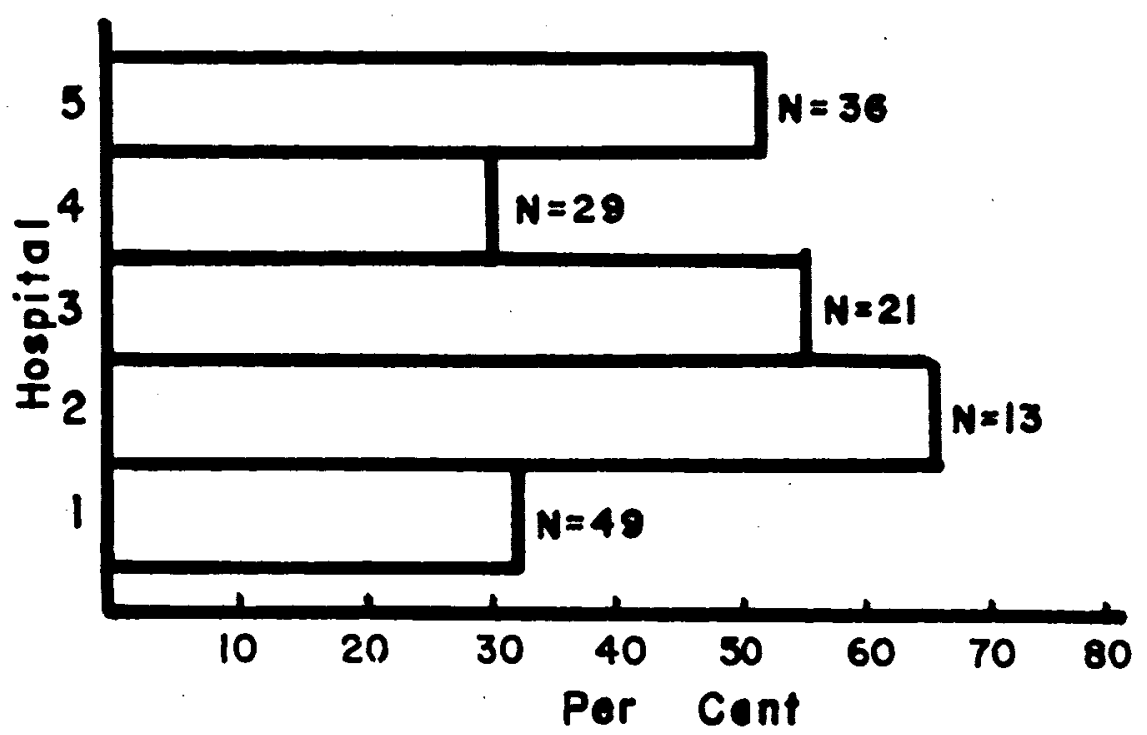

Figure 13. Per Cent Response of Nurses in Each Hospital Who Thought the Patient Would Benefit if They Were Strictly Medication Nurses

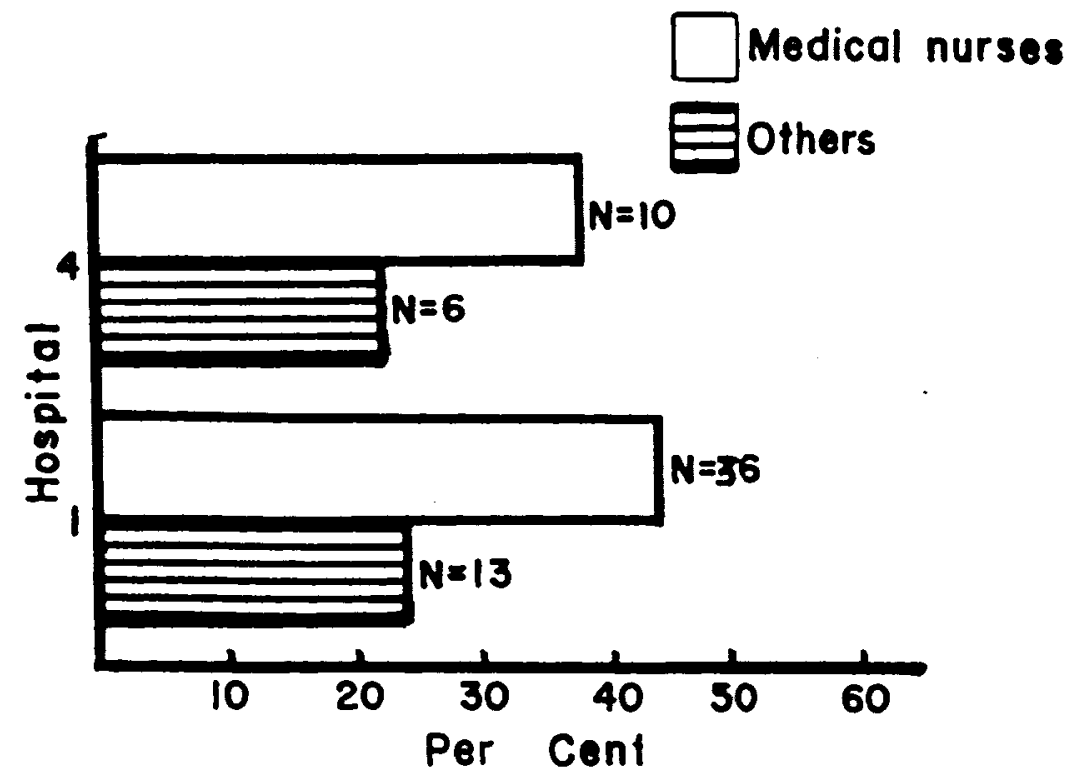

Figure 14. Per Cent of Medical Nurses in Hospitals (1) and (4) Who Felt the Patient Would Benefit if They Were Strictly Medication Nurses, Compared with Other Nurses in the Same Hospitals 
influence) operating in Hospitals (1) and (4). Table 7 shows the frequencies and expected frequencies of intensive care nurses. Table 8 shows the response by specialty for all nurses.

\section{Table 7}

Contingency Table of Intensive Care Nurses in Hospitals (1) and (4) and the Intensive Care Nurses in the Rest of the Hospitals As They Indicated whether the Patient Would Benefit from a Medication Nurse Specialty

\begin{tabular}{|c|c|c|c|}
\hline \multirow[b]{2}{*}{ Answers } & & \multicolumn{2}{|c|}{ Hospitals } \\
\hline & & Others & $1 \& 4$ \\
\hline Yes & $\begin{array}{l}\text { Obtained } \\
\text { Expected }\end{array}$ & $\begin{array}{l}28 \\
(20.1)\end{array}$ & $\begin{array}{l}18 \\
(25.9)\end{array}$ \\
\hline No & $\begin{array}{l}\text { Obtained } \\
\text { Expected }\end{array}$ & $\begin{array}{l}14 \\
(21.9)\end{array}$ & $\begin{array}{l}36 \\
(28.1)\end{array}$ \\
\hline & & & \\
\hline
\end{tabular}


Table 8

Per Cent Response of Each Specialty Group of Nurses Indicating whether the Patient Would Benefit if the Nurses Were Medication Specialists

\begin{tabular}{lccc}
\hline Specialty & \multicolumn{3}{c}{ Answer } \\
\cline { 2 - 4 } & $\frac{\text { Yes }}{\%}$ & $\frac{\text { No }}{\%}$ & Unable to Tabulate \\
Medical & 48 & 52 & 0 \\
Surgical & 42 & 58 & 0 \\
OB/GYN & 27 & 73 & 0 \\
Delivery & 45 & 55 & 0 \\
Emergency Room & 42 & 57 & 1 \\
Pediatrics & 29 & 71 & 0 \\
Nursery & 19 & 81 & 0 \\
Float & 22 & 78 & 0 \\
Intensive Care & 47 & 52 & 1 \\
\hline
\end{tabular}

University graduates were very consistent in their answers between hospitals. The answers given by nurses grouped by experience varied slightly. In general, nurses with $1-5$ years of experience and nurses with 10 or more years of experience tended to be most favorable toward the idea of medication nurses. Nurses with 5-10 years of experience were the least favorable. Of the 16 pharmacists, 14 felt the patient would benefit if some nurses were strictly medication nurses. 
Question (7). This question asked: (1) Should the pharmacist be unconcerned with problems of nursing and instead concentrate on problems of pharmacy; and (2) Is the pharmacist needed outside the four walls of the pharmacy, and should he be concerned with what happens at the nursing unit? There were no significant variances by category in regard to the ways the question was answered. All of the pharmacists felt they were needed outside the pharmacy and should be concerned with what happened at the nursing unit. Figure 15 shows the overall results for the nurse population.

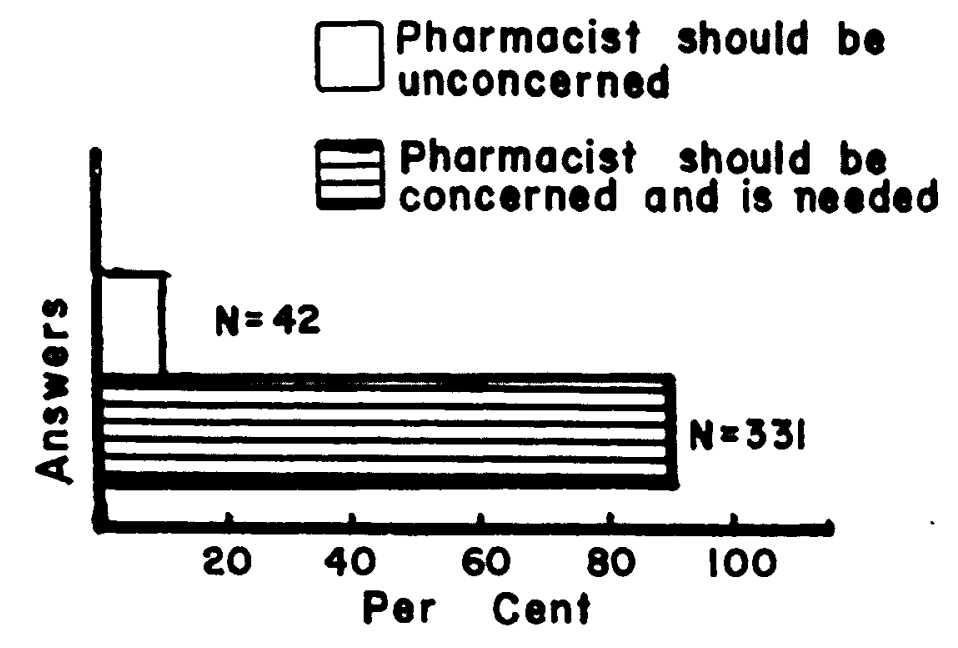

Figure 15. Per Cent Nurses Responding to whether Pharmacists Are Needed and Should Be Concerned with what Happens at the Nursing Unit 
The 11-7 shift nurses in Hospital (1) showed less tendency to say that the pharmacist should not be concerned than did nurses of the same shift in the other hospitals, as shown in Figure 16.

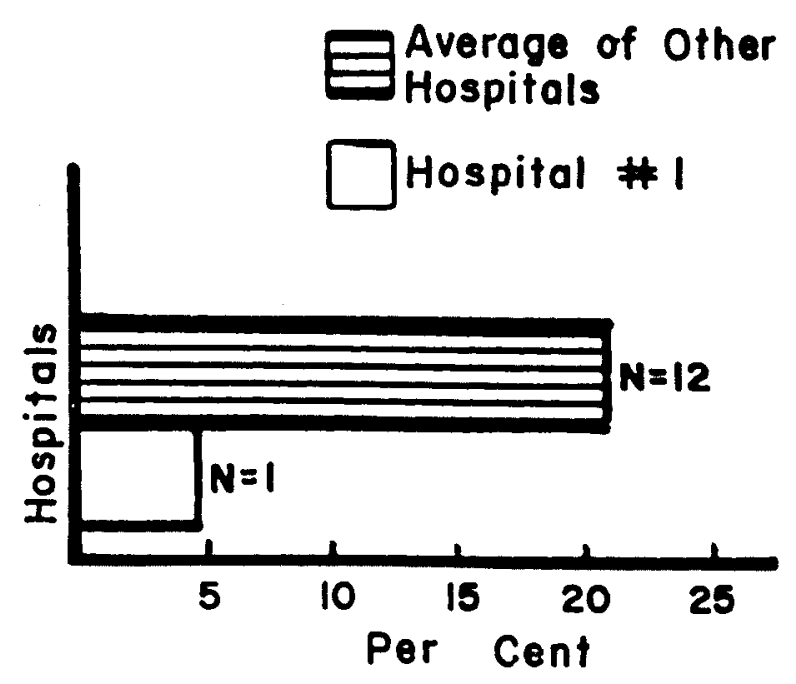

Figure 16. Per Cent of 11-7 Nurses Saying Pharmacists Should Be Unconcerned with Problems of Nurses, Hospital (1) Compared with Other Hospitals 
Question (8). The nurses were asked to indicate which activity would most improve pharmacy and nursing services. Table 9 shows that university graduates differed significantly from the average for the rest of the population $(p<.01)$. The answers were characteristic by shift at the .01 level. Only 18 per cent of the 3-11 shift nurses selected "ward conferences between pharmacists and nurses." No 11-7 nurses selected that answer. The answers by shift are shown in Table 10 .

\section{Table 9}

The Activity that Would Most Improve Pharmacy and Nursing Services, Per Cent Response Comparing University Graduates with Rest of Population

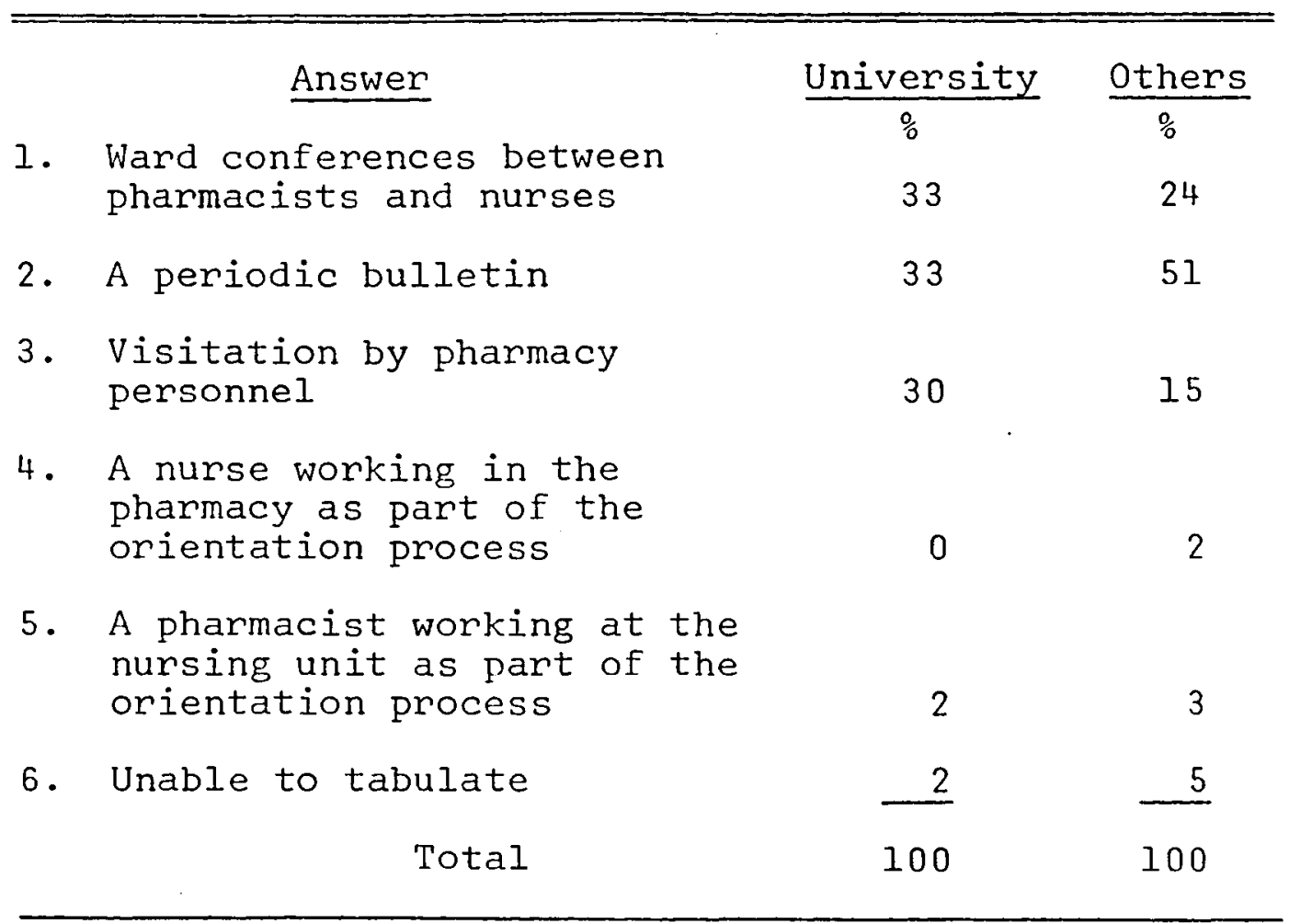


Table 10

The Activity that Would Most Improve Pharmacy and Nursing Services, Per Cent Response by Nursing Shift

\begin{tabular}{|c|c|c|c|c|}
\hline & Answer & $\underline{7-3}$ & $\frac{\text { Shift }}{3-11}$ & $11-7$ \\
\hline & & $\%$ & $\%$ & $\%$ \\
\hline 1 . & $\begin{array}{l}\text { Ward conferences between } \\
\text { pharmacists and nurses }\end{array}$ & 28 & 18 & 25 \\
\hline 2. & $\begin{array}{l}\text { A periodic bulletin from } \\
\text { pharmacy }\end{array}$ & 42 & 55 & 64 \\
\hline 3. & $\begin{array}{l}\text { Visitation by pharmacy } \\
\text { personnel, at the nursing } \\
\text { unit }\end{array}$ & 18 & 20 & 0 \\
\hline 4. & $\begin{array}{l}\text { A nurse working in the } \\
\text { pharmacy as part of the } \\
\text { orientation process }\end{array}$ & 3 & 3 & 1 \\
\hline 5. & $\begin{array}{l}\text { A pharmacist working at the } \\
\text { nursing unit as part of the } \\
\text { orientation process }\end{array}$ & 4 & 2 & 1 \\
\hline 6 . & Unable to tabulate & 5 & 2 & 9 \\
\hline & Total & 100 & 100 & 100 \\
\hline
\end{tabular}

The high desire for bulletins on the part of the 1I-7 shift was consistent for all hospitals. Hospital (1), with a pharmacist on duty on the $11-7$ shift, showed 73 per cent of the nurses on that shift preferring to have a bulletin. The demand for a bulletin seemed to increase as the opportunity for nurse-pharmacist contact decreased due to pharmacy staffing patterns. Nine pharmacists thought that visitation by pharmacists at the nursing station would most improve 
nursing and pharmacy services. Four chose ward conferences, and the other three chose the bulletin.

Question (9). The nurses chose which activity they felt was most unrelated to their duties as nurses. The results showing the two most frequently selected answers by all nurses are depicted in Figure 17.

\section{Calling Doctors About \\ Medications}

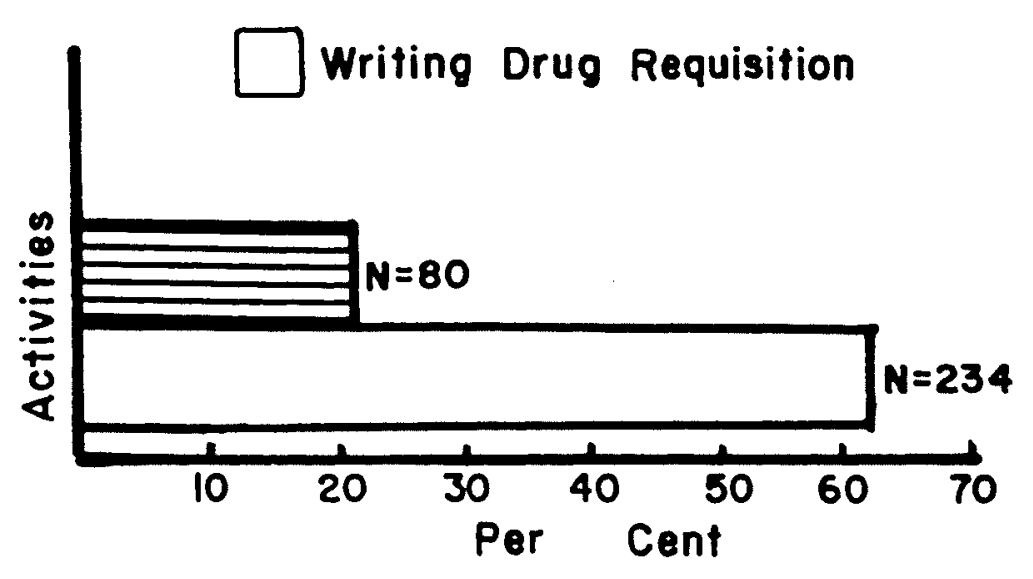

Figure 17. Per Cent Nurses Indicating the Two Activities Most Unrelated to the Duties of a Nurse 
There was a trend as nurses became more experienced to change perceptions of duties. This was significant at the .01 level. Telephoning physicians was seen as a duty less frequently as the experience increased. Nurses who had been in practice more than 20 years indicated that writing requisitions was more related to their duties than did other nurses, as shown in Figure 18.

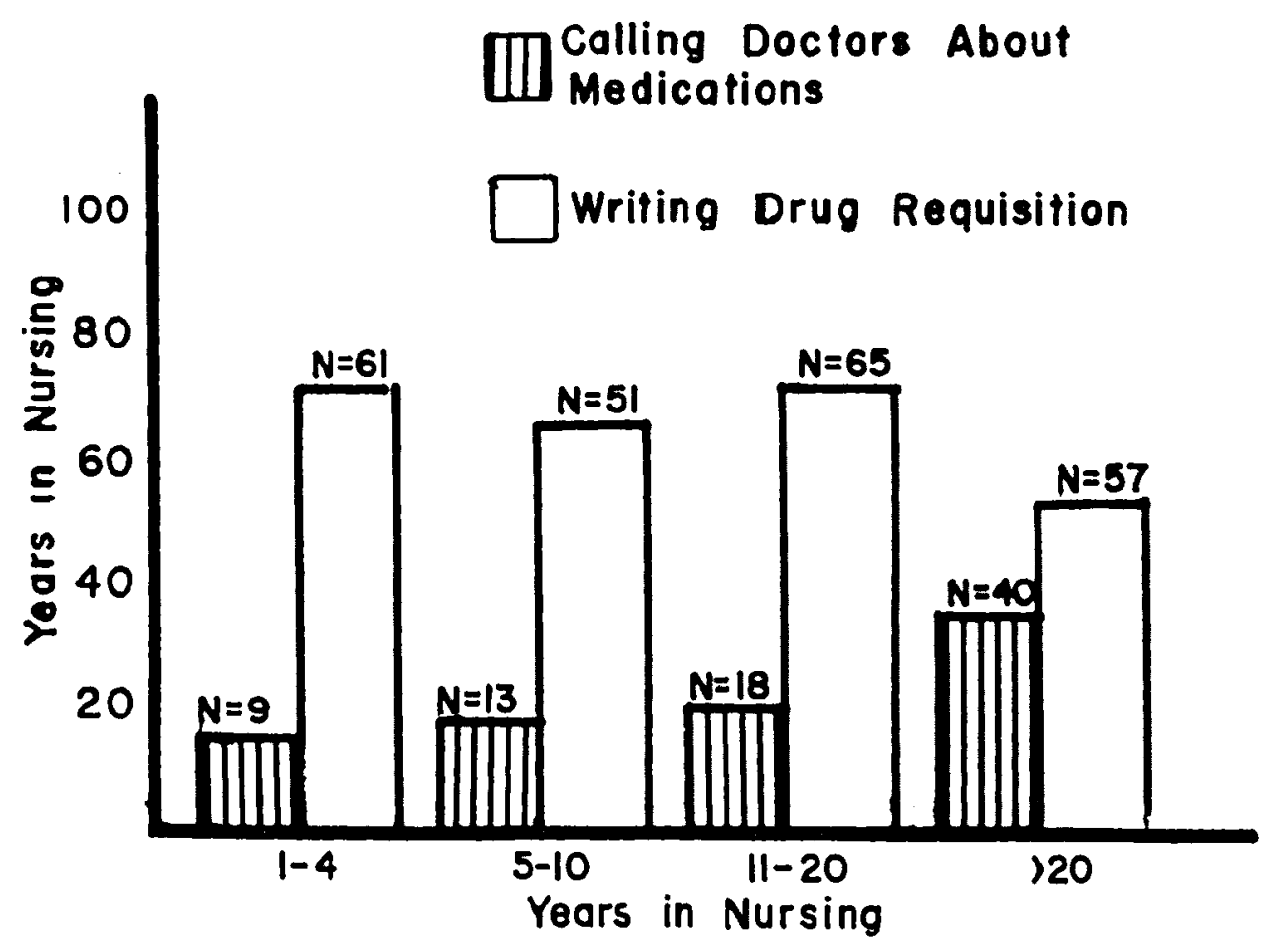

Figure 18. Per Cont Nurses Indicating the Two Activities Most Unrelated to Their Duties, As a Function of Tixperience 
The functions of diluting injectable medications, preparing medications, and mixing intravenous solutions were evidently more related to the perceived role. The per cent response to these activities ranged from 2-5 per cent. "Telephoning physicians with medication questions" was picked by seven pharmacists. Four picked "writing drug requisitions," three chose "preparing medications," and the other two chose "mixing I.V. solutions."

Question (10). Each nurse indicated how often she conferred with a pharmacist for drug information. Answers varied significantly by (1) hospital, (2) level of supervision, (3) shift worked, (4) specialty, and (5) tenure. Answers for the whole population are illustrated in Figure 19.

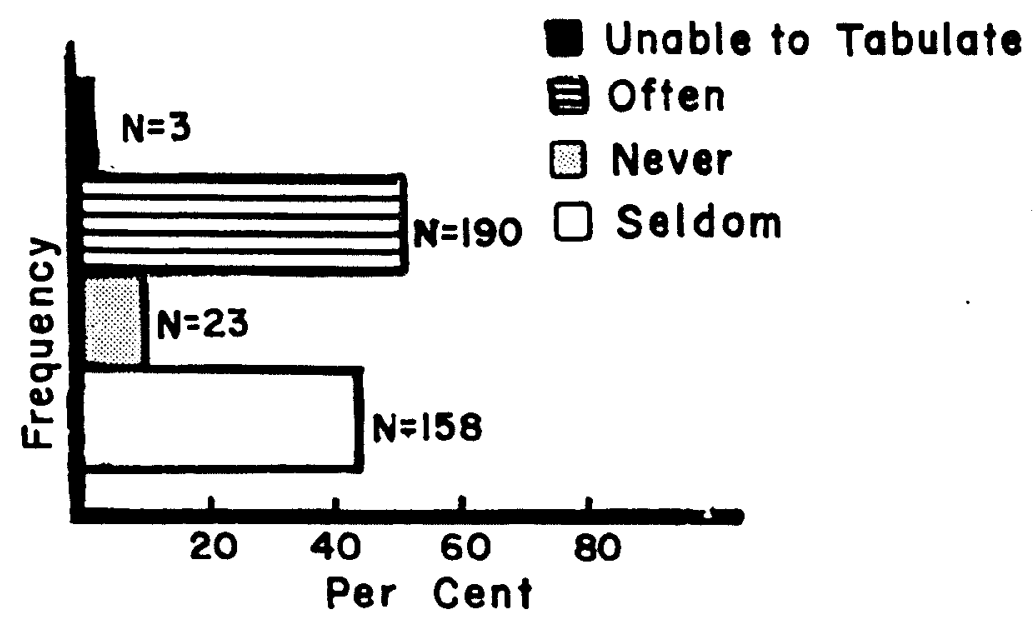

Figure 19. Per Cent of Total Population of Nurses Indicating How Often They Confer with a Pharmacist for Drug Information 
The nurses in the smallest hospitals, (2) and (3), conferred the least with pharmacists for drug information. These nurses also rated pharmacy as being the poorest source of information, as shown in Figure 5. Nurses in the langest hospitals, (1) and (5), showed a tendency to confer with pharmacy most often (Figure 20).

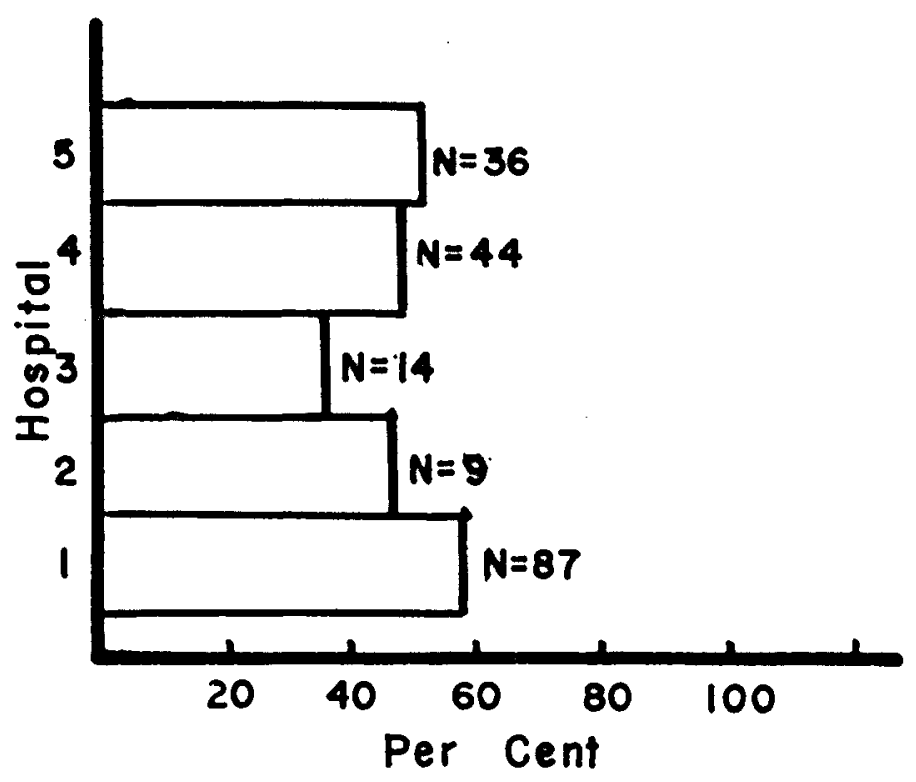

Figure 20. Per Cent of Nurses in Each Hospital Who Confer Often with Pharmacists 
There was not a particularly strong relationship between level of supervision and amount of personal contact with a pharmacist for drug information $(C=.15)$. Assistant head nurses conferred the most ( 65 per cent saying "often") and team leaders conferred the least ( 47 per cent saying "often").

The shift worked determined the frequency at a significancy level of .01 . The strength of the relationship was very high $(C=.44)$. Table 11 shows the answers as given by shift.

Table 11

Per Cent of Nurses on Each Shift Indicating How Often They Confer with a Pharmacist for Drug Information

\begin{tabular}{|c|c|c|c|c|}
\hline \multirow[b]{2}{*}{ Answer } & \multicolumn{4}{|c|}{ Shift } \\
\hline & $\frac{7-3}{\frac{0}{0}}$ & $\frac{3-11}{\frac{0}{0}}$ & $\frac{11}{\frac{1}{6}}-7$ & ${\frac{11-7^{\mathrm{a}}}{6}}^{\mathrm{a}}$ \\
\hline Seldom & 40 & 44 & 45 & 50 \\
\hline 2. Never & 0 & 1 & 27 & 41 \\
\hline 3. Often & 59 & 55 & 26 & 7 \\
\hline Unable to tabulate & 1 & 0 & 2 & 2 \\
\hline Total & 100 & 100 & 100 & 100 \\
\hline
\end{tabular}

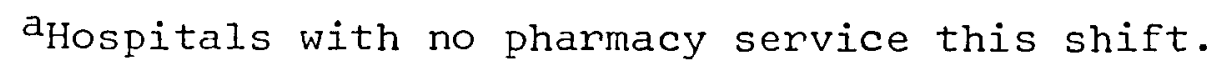


Surgical nurses conferred with a pharmacist most often. Delivery room nurses conferred the least. The relationship between specialty and answer was not exceptionally strong $(C=.30)$. Table 12 shows the results by specialty.

\section{Table 12}

Per Cent of Nurses in Each Specialty

Indicating How Often They Confer

with a Pharmacist for Drug Information

\begin{tabular}{|c|c|c|c|c|}
\hline \multirow[b]{2}{*}{ Specialty } & \multicolumn{4}{|c|}{ Answer } \\
\hline & Seldom & Never & Often & Tabulate \\
\hline & $\frac{\%}{0}$ & $\%$ & $\%$ & $\%$ \\
\hline Medical & 38 & 5 & 57 & 0 \\
\hline Surgical & 29 & 4 & 67 & 0 \\
\hline Obstetrical/Gyn. & 47 & 0 & 53 & 0 \\
\hline Delivery & 45 & 27 & 18 & 10 \\
\hline Emergency Room & 65 & 8 & 27 & 0 \\
\hline Pediatrics & 43 & 11 & 46 & 0 \\
\hline Nursery & 69 & 13 & 13 & 5 \\
\hline Float & 41 & 6 & 53 & 0 \\
\hline Intensive Care & 42 & 4 & 53 & 1 \\
\hline
\end{tabular}

Nurses with the least tenure seemed to use the consultation of the pharmacist less than did those with more tenure, as shown in Figure 21. There was no corresponding question on the questionnaire sent to the pharmacists. 


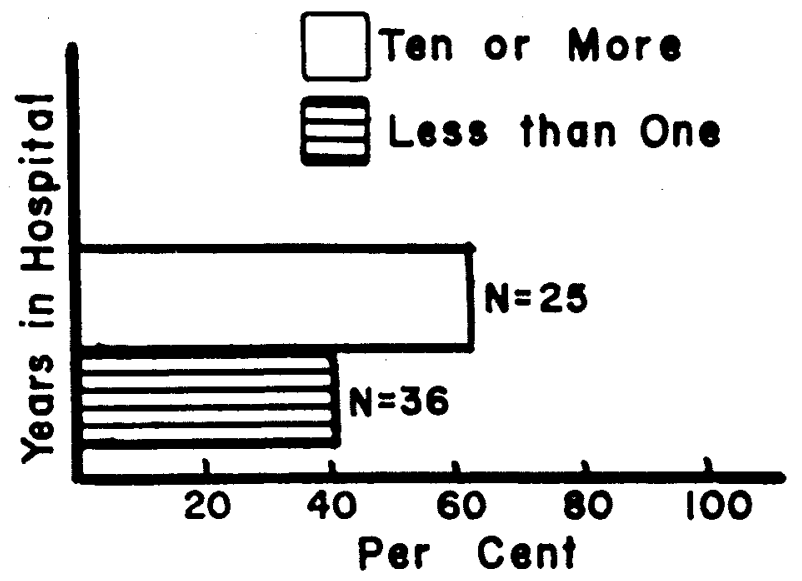

Figure 21. Per Cent of Nurses Grouped by Tenure Saying They Conferred Often with a Pharmacist for Drug Information 
Question (11). The nurses were asked to choose the area in which they felt most inadequate. When examined as a total group, the nurses felt the least adequate in the knowledge of which drugs could be used together. Figure 22 shows that the second most frequent answer was "pharmaceutical calculations."

Answers varied significantly by specialty $(p<.025)$. The significance seemed to rest in the selection of "pharmaceutical calculations" and "knowledge of which drugs can be used together." Medical and intensive care nurses answered the questions in the same fashion as shown in Figure 22. The other groups preferred one answer or the other depicted in Table 13. 


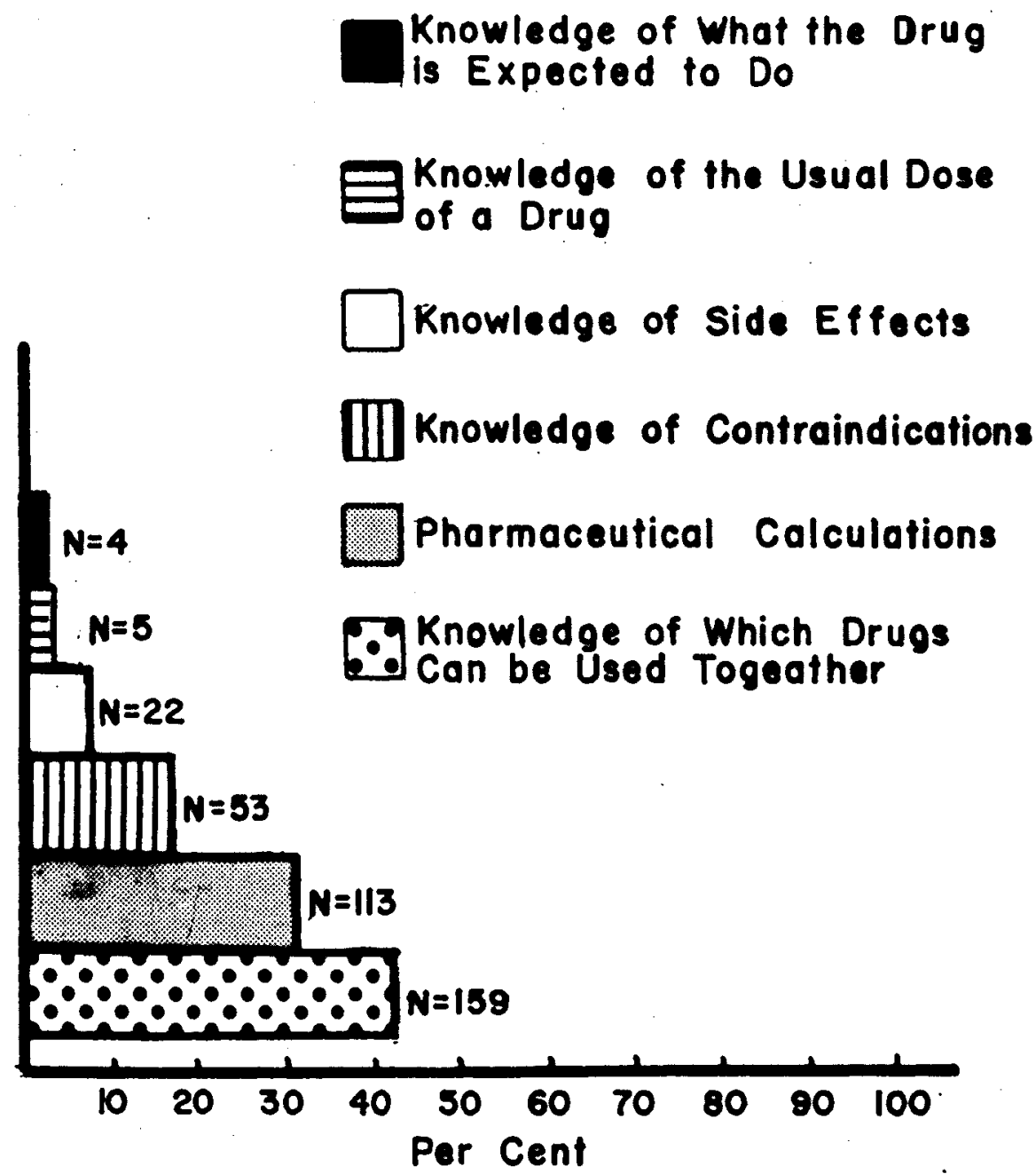

Figure 22. Areas in which Nurses Felt Least Adequate, Per Cent of Population Selecting Each Area 
"Which drugs can be used together" and "contraindications" were selected by six and four pharmacists respectively. The other alternatives received one or two preferences each.

Table 13

Specialty Nurses Who Differed from the Group As a Whole As They Selected Either "Pharmaceutical Calculations" or "Knowledge of Which Drugs Can Be Used Together" As Areas in Which They Felt Least Adequate

\begin{tabular}{ll}
\hline $\begin{array}{l}\text { Pharmaceutical } \\
\text { Calculations: }\end{array}$ & $\begin{array}{l}\text { Which Drugs Can Be } \\
\text { Used Together: }\end{array}$ \\
\hline $\begin{array}{l}\text { Surgical (+) } \\
\text { Delivery Room (+) } \\
\text { Obstetrics/Gyn. (-) }\end{array}$ & Pediatrics (+) \\
Pediatrics (-) & Float (+) \\
Nursery (-) & \\
Float (-) & \\
\hline & \\
$(+)$ Significantly more nurses \\
\hline
\end{tabular}

Question (12). An overwhelming number (97 per cent) of the nurses felt that the purpose of the pharmacy service should be to first serve the health and well-being of the patient. The other 3 per cent felt the purpose should be to serve the physician. All of the pharmacists said the purpose should be to first serve the health and well-being of the patient.

Question (13). Each nurse chose the service that she would most welcome. The response to each answer varied 
significantly $(p<.05)$ by hospital. The significance was attributed to the values placed on drug information and the presence of a pharmacist. Nurses in Hospitals (4) and (5) selected the answers in almost an identical fashion. Both of these hospitals were operated by the same religious order. Hospital (4) was constructed as a sister hospital to Hospital (5). The effect of philosophy of administration on the staff was mentioned by OIson (1968, p. 350-351); Smith (1965, p. 196); and Baziak (1968, p. 153).

Table 14 shows how each level of supervision and hospital responded. The level of supervision was a significant factor at the .01 level, and examination of the expected values revealed that Hospital (1) influenced the results. Hospital (1) furnished 10 of the 22 head nurses and 20 of the 30 assistant head nurses who preferred drug information with each new drug order. These nurses represented 50 per cent of the head nurses and 66 per cent of the assistant head nurses in Hospital ( 1 ). This trend was not observed in the other hospitals. Team leaders did not vary much in their answers among hospitals. Pre-diluted injectable materials were desired at about the same frequency regardless of hospital on level of supervision.

Eight pharmacists thought that a pharmacist available to answer questions would be the most desired service. Five pharmacists chose "I.V. additive service," and the rest chose "Information with each new drug order." 
Table 14

Per Cent of Nurses in Each Hospital and Level of Supervision Selecting the Service that Would Be Most Welcome

\begin{tabular}{|c|c|c|c|c|c|c|c|c|}
\hline \multirow{3}{*}{ Service } & \multicolumn{5}{|c|}{ Hospital } & \multicolumn{3}{|c|}{ Level } \\
\hline & $\frac{1}{0}$ & 2 & 3 & 4 & 5 & $\begin{array}{l}\text { Head } \\
\text { Nurse }\end{array}$ & $\begin{array}{l}\text { Asst. } \\
\text { H.N. }\end{array}$ & $\begin{array}{c}\text { Team } \\
\text { Leader } \\
\end{array}$ \\
\hline & $\%$ & $\%$ & $\%$ & $\%$ & $\%$ & $\%$ & $\%$ & $\%$ \\
\hline Drug Information & 52 & 20 & 46 & 40 & 37 & 32 & 59 & 44 \\
\hline I.V. Additives & 8 & 25 & 13 & 5 & 9 & 18 & 4 & 7 \\
\hline $\begin{array}{l}\text { Pharmacist } \\
\text { Available }\end{array}$ & 12 & 15 & 10 & 27 & 21 & 15 & 6 & 21 \\
\hline $\begin{array}{l}\text { Pre-Diluted } \\
\text { Injections }\end{array}$ & 24 & 35 & 28 & 26 & 26 & 32 & 29 & 24 \\
\hline $\begin{array}{l}\text { Unable to } \\
\text { Tabulate }\end{array}$ & 4 & 5 & 3 & 2 & 7 & 3 & 2 & 4 \\
\hline
\end{tabular}

Question (14). The nurses were asked to rate the pharmacy service in their respective hospitals. Most nurses felt that the pharmacy services were "adequate." Results are shown in Figure 23. 


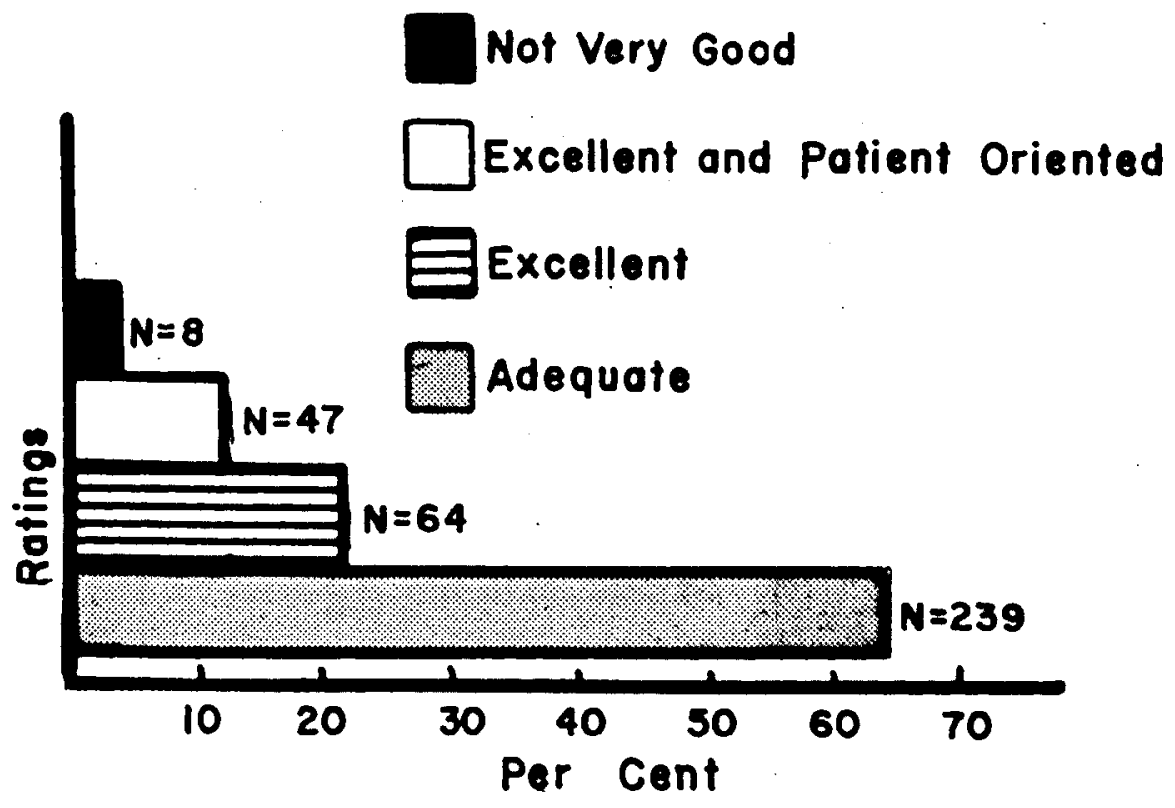

Figure 23. Per Cent of Nurses Choosing Each Rating As They Evaluated the Pharmacy Services 
The number of years of experience of each nurse seemed to play a significant part in her decision ( $\mathrm{p}<.01)$. Fewer younger nurses tended to rate the service as "excellent" than did the older nurses, as shown in Figure 24 .

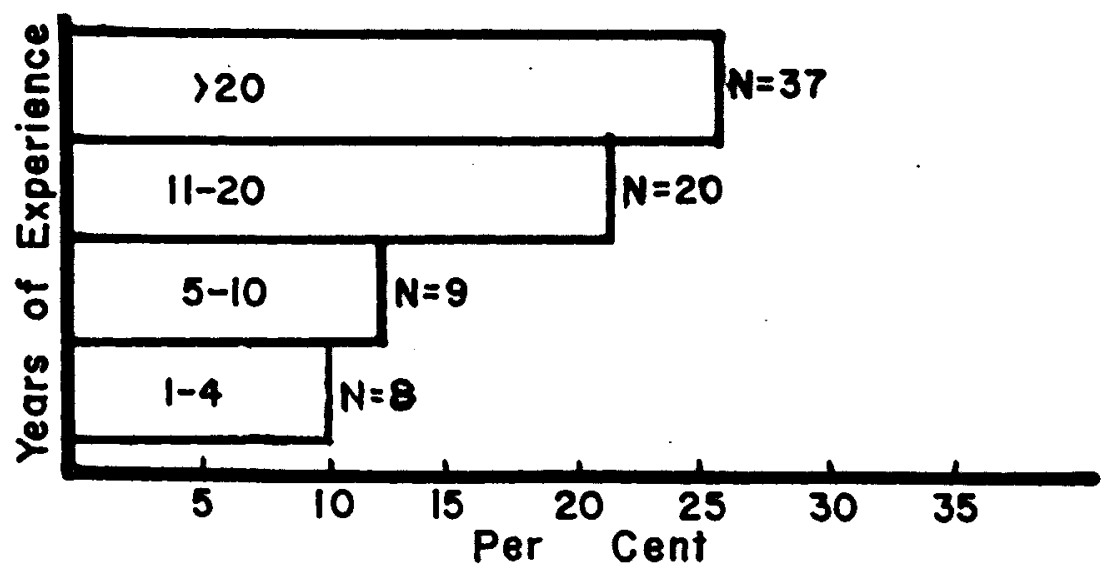

Figure 24. Per Cent of Nurses in Each Experience Interval Who Rated the Pharmacy Services "Excellent" 
Tenure also significantly affected the answers at the .05 level. Nurses who had been working in their respective hospitals for 10 or more years tended to rate the pharmacy services as "excellent" (see Figure 25).

About 19 per cent of the nurses in Hospital (1) on the 1l-7 shift felt the pharmacy service was "excellent and patient-oriented." This compared with 6 per cent of the 11-7 nurses in the other hospitals. Of the 11-7 nurses in Hospital (I), 31 per cent rated the pharmacy services as "excellent," as compared with 17 per cent of the 11-7 nurses in the other hospitals.

Seven pharmacists thought their pharmacy service was "adequate"; four said "excellent"; and one said "excellent and patient-oriented." The rest said "not very good."

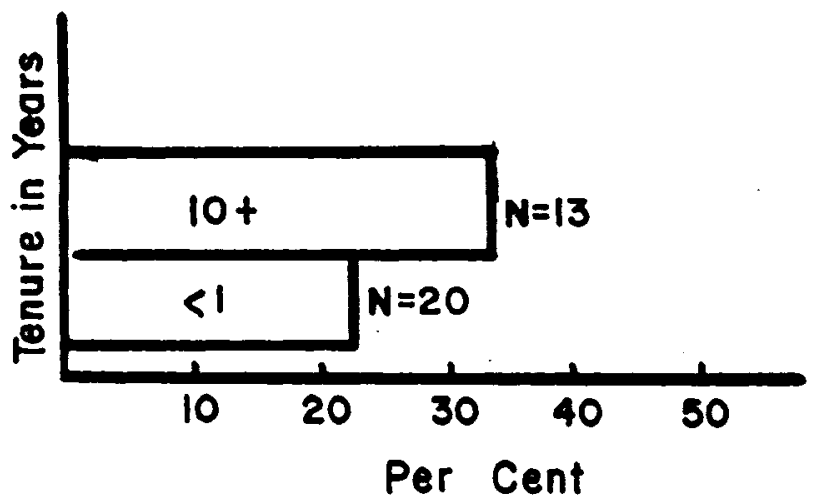

Figure 25. Per Cent of Nurses in Each Tenure Interval Who Rated the Pharmacy Services "Excellent" 
Question (15). When asked to choose what they disliked most about handling drugs, 20 per cent of the nurses did not answer. This question was evidently not a good one. Many nurses indicated they were upset and felt neither answer really gave any choice. Some who wrote comments were very defensive: "If I felt 'insecure and inadequate' I would not be giving meds." This suggested that the question was too direct and was probing a sensitive area.

Question (16). The question asked if nurses and pharmacists should work together and if there were needs that one discipline could meet for the other. Figure 26 shows that most nurses showed a receiving attitude rather than a give and take perception of pharmacy-nursing relationships. Nearly all nurses felt there should be a working relationship with pharmacy. This picture was true for all classifications of nurses.

"Pharmacists and nurses should work together" was indicated by five of the 16 pharmacists. The rest said "nurses and pharmacists should work together, and nurses could contribute to the quality of pharmacy service." 
There is a Need for Pharmacist and Nurses to Work Togethier and Nurses Can Contribute to Pharmacy Service

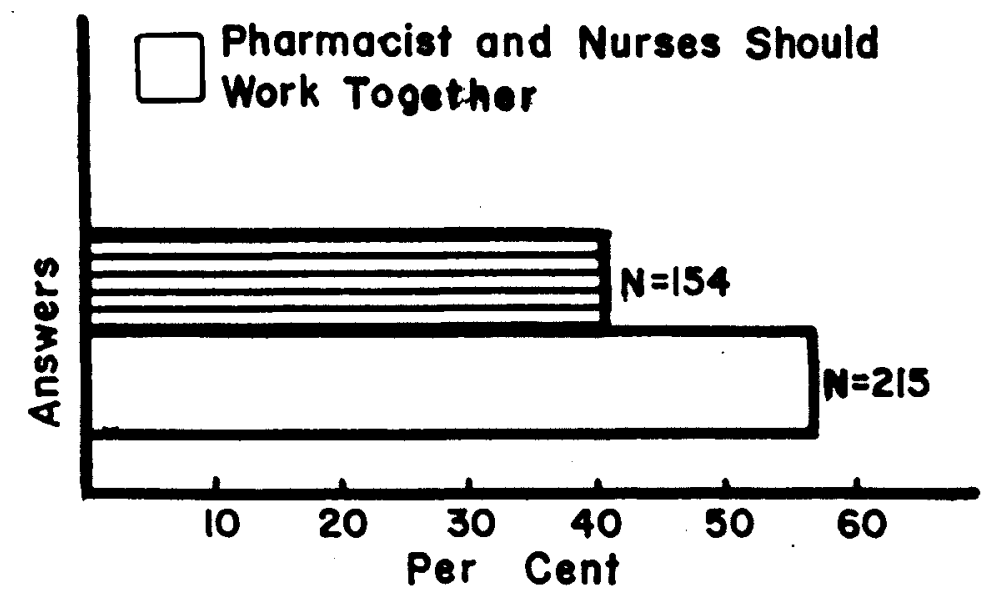

Figure 26. Per Cent of All Nurses Indicating if They Felt Pharmacy and Nursing Should Work Together. The Two Most Frequently Selected Answers Depicted 
Question (17). The nurses were asked if they perceived pharmacists to be interested in what happened in the rest of the hospital and if pharmacists were well-informed. The greatest percentage of nurses felt that pharmacists were interested and well-informed. Figure 27 shows that the second greatest percentage thought that pharmacists were interested but poorly-informed.

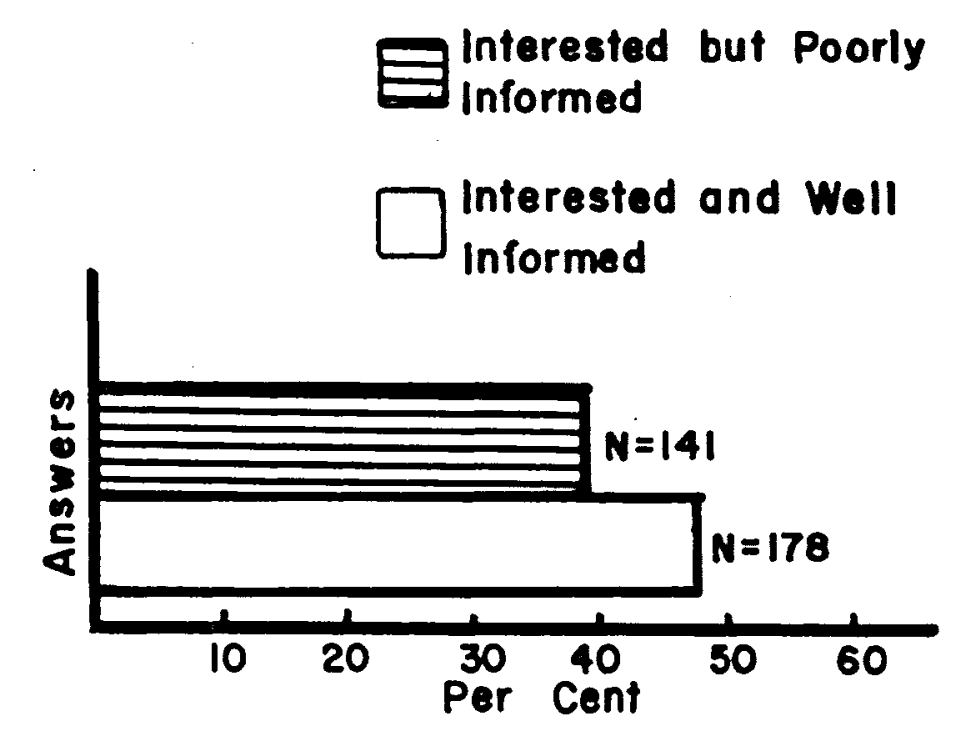

Figure 27. Per Cent of All Nurses Indicating if Pharmacists Were Interested in the Rest of the Hospital and if the Pharmacists Were Well Informed. The Two Most Frequently Selected Answers Depicted 
A characteristic pattern of answers attributed to the 3-1l nurses in general was significant at the .05 level. Those nurses tended to describe pharmacy as "not interested" to a greater degree than did the other nurses. This is shown in Figure 28.

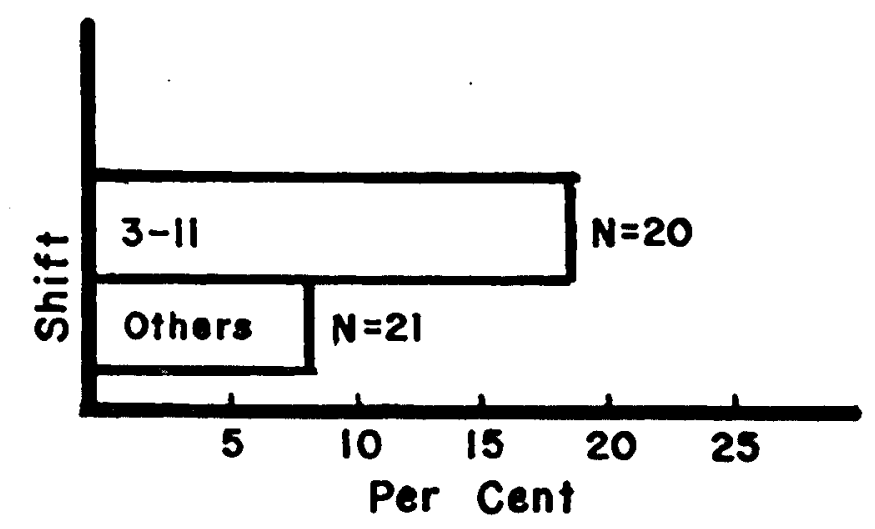

Figure 28. Per Cent of 3-11 Shift Nurses Compared with All Other Nurses As They Perceived Pharmacists Not Being Interested in what Happened in the Rest of the Hospital 
As nurses became older, they tended. to perceive pharmacists as being more interested. This tendency was particularly noticeable in nurses who had 11 or more years of experience and was significant at the .02 level. This pattern can be seen in Figure 29.

University graduates were more critical of pharmacists than the rest of the population $(p<.05)$. Of the uni- . versity graduates, 68 per cent thought pharmacists were not interested or not well-informed.

Twelve pharmacists thought they were interested but not very well-informed. The other four thought they were interested and well-informed. 
Years in Nursing

$$
\begin{aligned}
& 1-4 \\
& 5-10 \\
& 11-20 \\
& 20+
\end{aligned}
$$

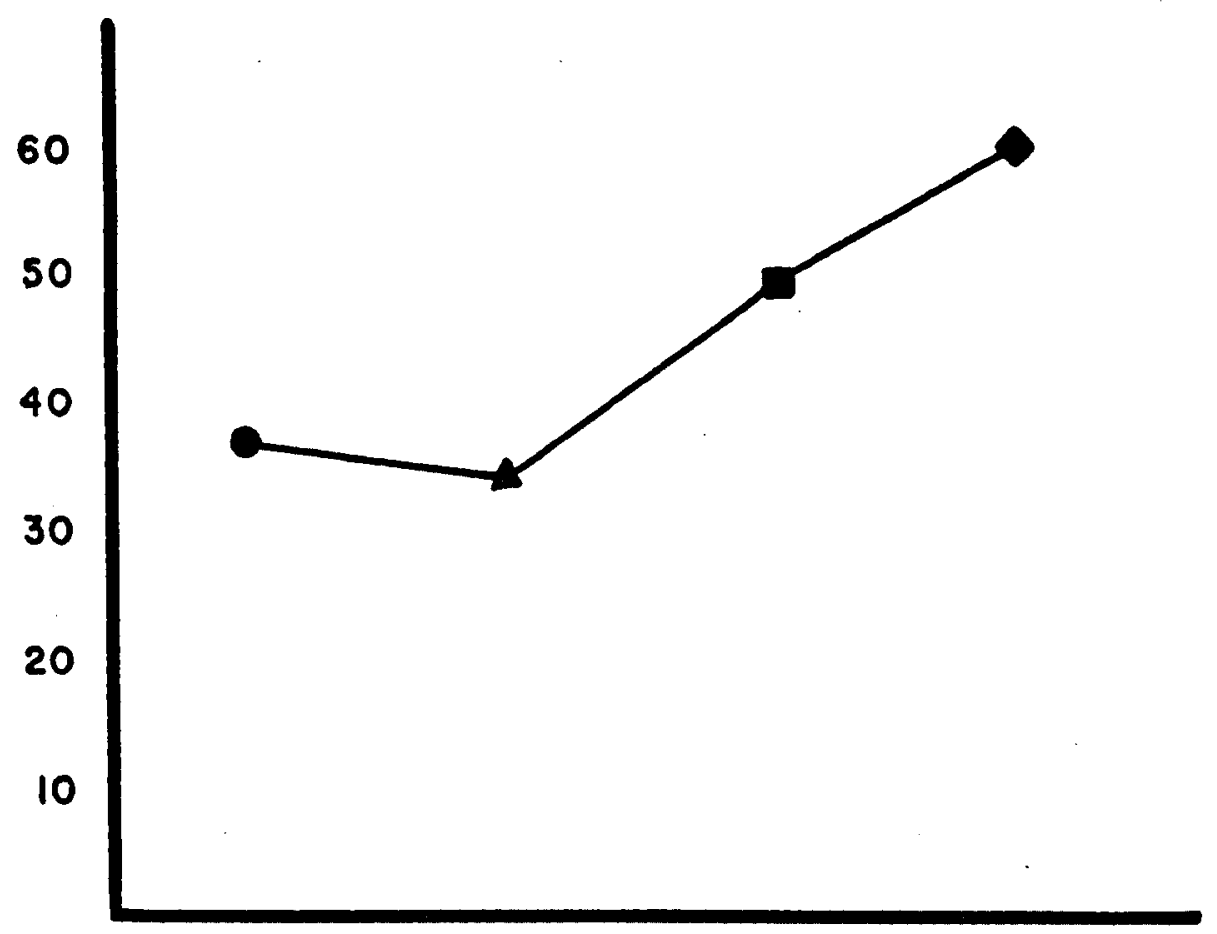

Figure 29. Per Cent of Each Experience Group of Nurses That Perceived Pharmacists As Being Interested in What Happened in the Rest of the Hosnital 
Question (18). The nurses selected the most desirable quality of a pharmacist in their opinions. None of the specified groups of nurses answered the question in a statistically significant manner. However, there were some apparent deviations within each group.

The nurses in Hospital (4) showed a high preference for "accuracy" as the most desirable quality of a pharmacist. Figure 30 shows Hospital (4) compared with the other hospitals. This value was thought to be instilled by nursing administration during a recent campaign to reduce medication errors. The nurses may have been assigning these desirable qualities to the pharmacists.

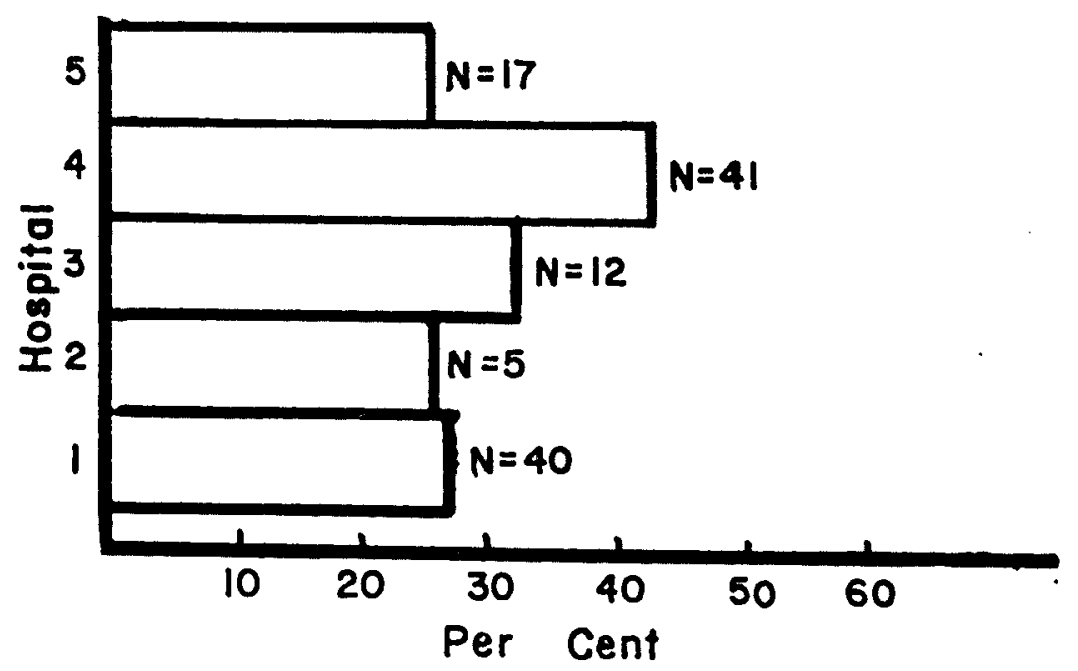

Figure 30. Per Cent of Nurses in Each Hospital That Chose "Accuracy" As the Most Desirable Quality of a Pharmacist 
The head nurses and assistant head nurses showed a high preference for a cooperative pharmacist as shown in Figure 31. This reinforced the study by Smith (1965, p. 198200) who found that supervisory nurses stressed cooperation to a greater extent than did the nursing educators.

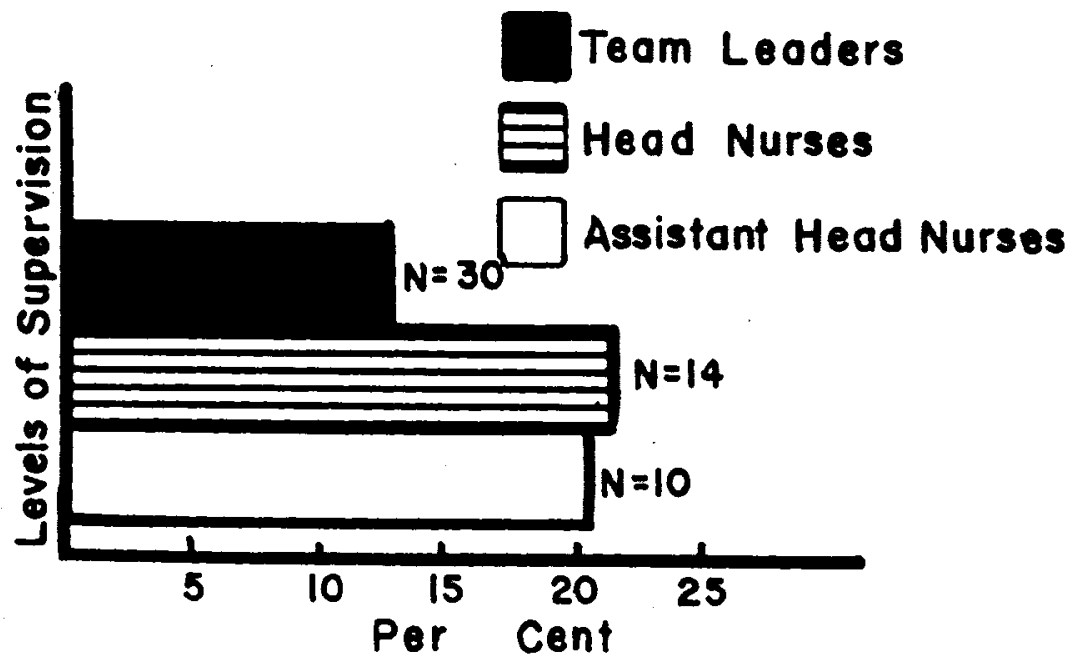

Figure 31. Per Cent of Nurses at Each Level of Supervision Who Chose "Cooperative" As the Most Desirable Quality of a Pharmacist 
Medical and surgical nurses differed in their views of desired qualities of pharmacists. The differences are pictured in Figure 32. Surgical nurses were described by Lentz and Michaels (1960) as being more technically oriented than medical nurses. To be a good surgical nurse implied placing an emphasis on routine technical tasks rather than on medications. The same values were placed on pharmacists by the surgical nurses.

Exactly 50 per cent $(N=26)$ of the emergency room nurses chose "expert and efficient in the technical aspects of work." This seemed to be a desirable quality of emergency room nurses, who had to react in that manner in moments of crisis and see to it that space and equipment were highly utilized at busy times.

In the overall results for all answers, "Showing concern for others" and "being an independent thinker" ranked very low with less than 2 per cent and $I$ per cent each. "Being expert in the technical aspects of the work" gathered 29 per cent of the vote, while "accuracy" was right behind with 28 per cent. "Knowledgeable about drugs" and "a cooperative attitude" received the votes of 19 per cent and 15 per cent of the nurses respectively.

Seven pharmacists selected "being expert and efficient in the technical aspects of work" as the most desirable quality of a pharmacist. "A cooperative attitude" was 
chosen by four pharmacists, and the others divided among the other choices.

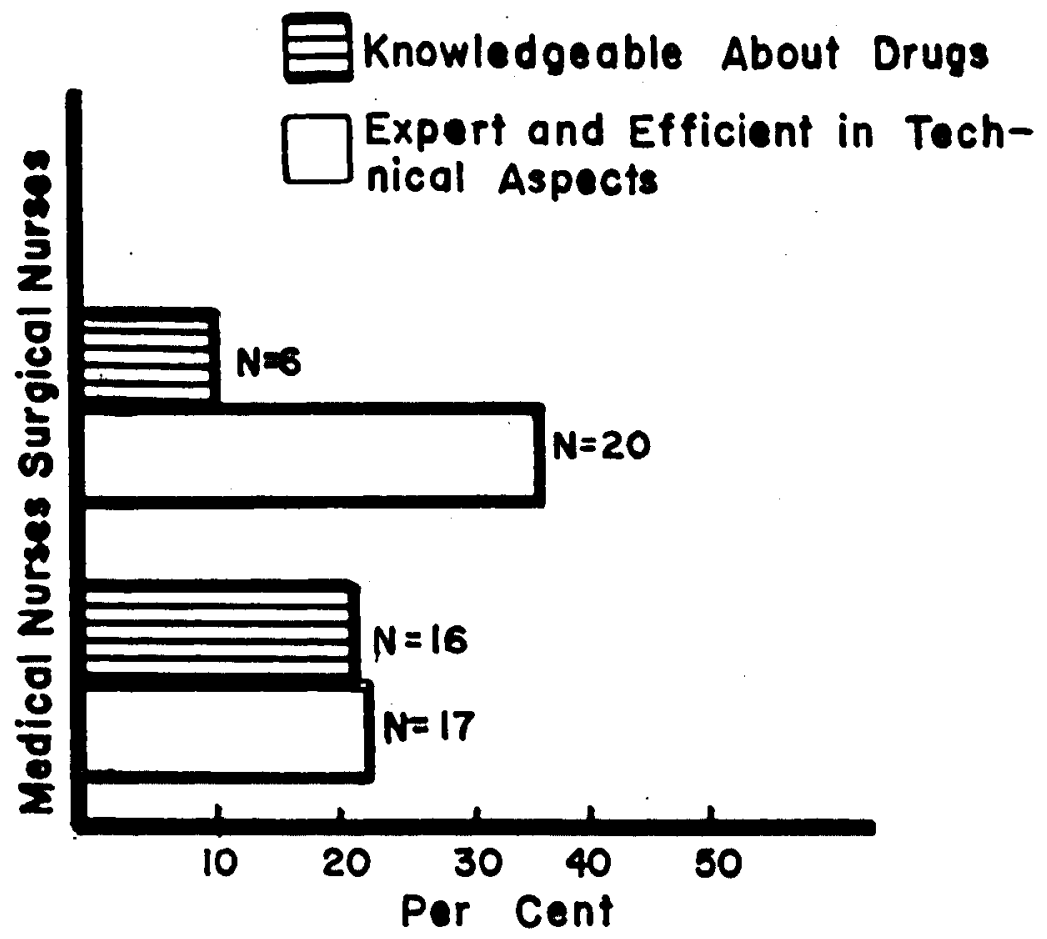

Figure 32. Percentages of All Medical and Surgical Nurses Placing Importance on Knowledge about Drugs and the Technical Aspects of Work As Desirable Qualities of Pharmacists 
Question (19). Each nurse was asked to identify the cause of most problems with pharmacy. All groups answered in nearly the same manner as shown in Figure 33. However, a trend according to tenure was noted. Figure 34 illustrates that as a nurse accumulated more years in a hospital, she had less tendency to say "there are too many technicalities and petty rules" and an increased tendency to say "no problems."

Nine pharmacists said most problems arise with nurses because of lack of understanding of each other's work. The other seven said poor communication existed on a staff level. Question (20). An overwhelming number of nurses ( 93 per cent) felt that pharmacists could possibly understand the problems associated with nursing. Fourteen of the 16 pharmacists were in agreement with the nurses. 


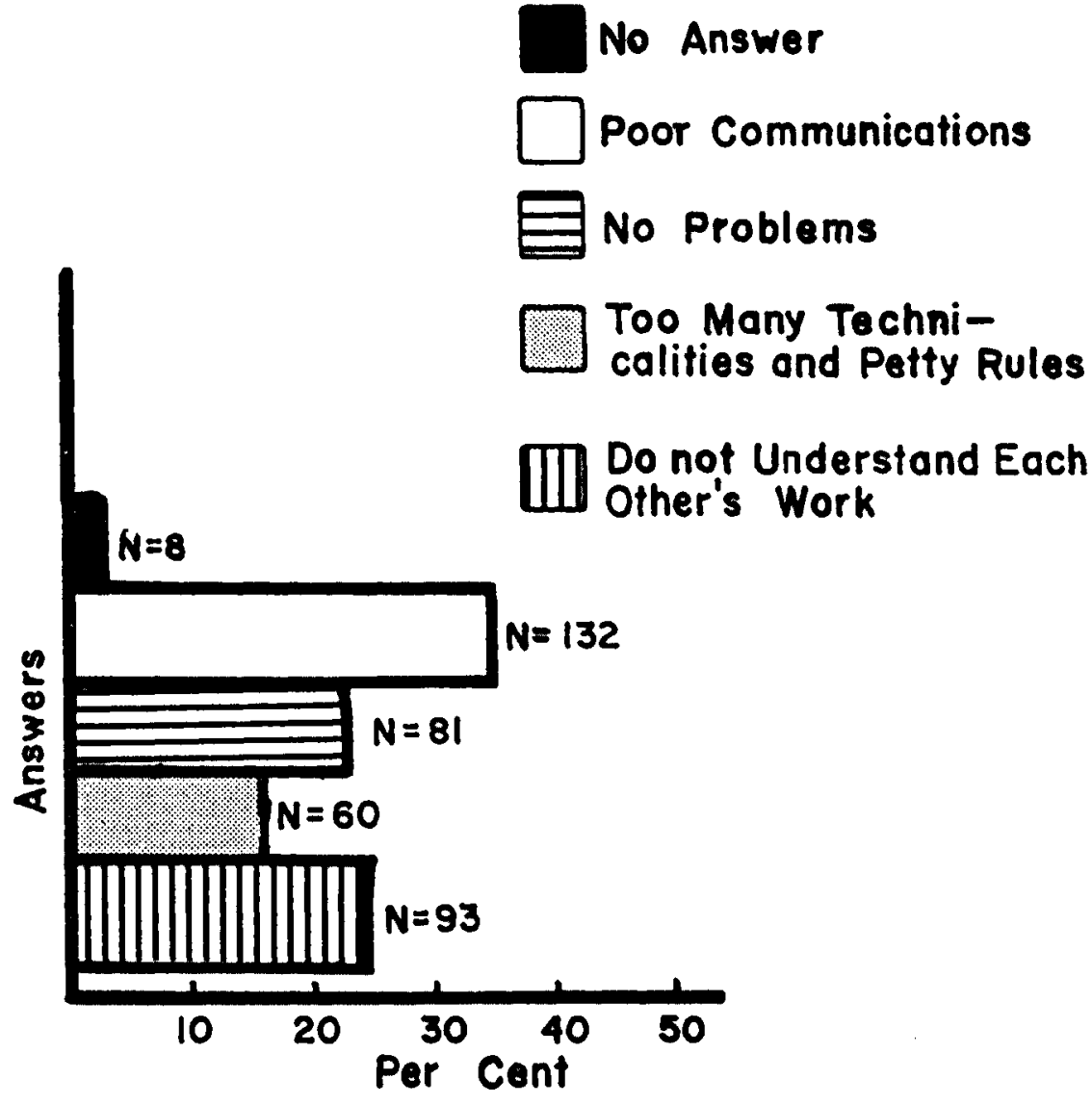

Figure 33. Per Cent of All Nurses Identifying, Each Cause of Most Problems with Pharmacy 


\section{Too Many Technicalities and Petty Rules}

$\square$ No Problems

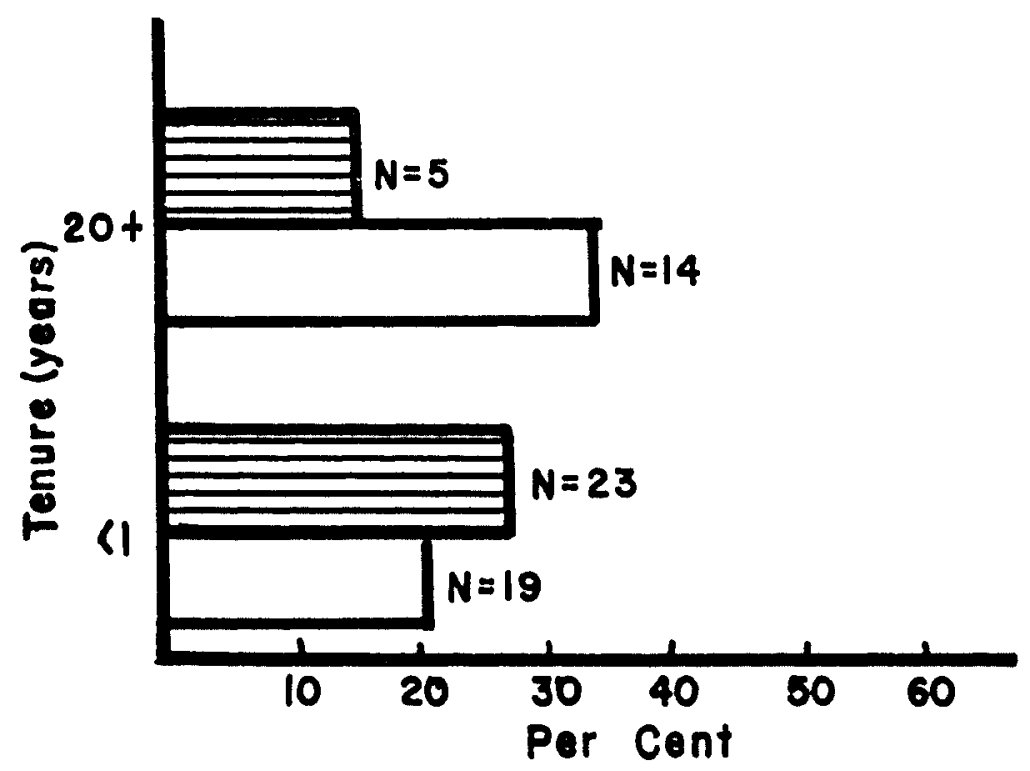

Figure 34. Per Cent of Nurses in Each Tenure Group Identifying "No Problems" with Pharmacy or "Technicalities and Rules" As Causes of Problems 
CHAPTER 3

SUMMARY, CONCLUSIONS; RECOMMENDATIONS

This chapter combines the findings of the surveys, summarizes the major points, and makes recommendations. The overall results, significant differences among the defined nursing categories, and the levels of agreement between nurses and pharmacists are discussed.

\section{Summary and Conclusions}

Supported by the fact that 89 per cent of the nurses said that pharmacists should be concerned about what happens in the rest of the hospital and are needed there, it was concluded that pharmacists had a role to play outside the pharmacy. This conclusion was further supported by 98 per cent of the nurses who indicated that pharmacists and nurses should work together. A large number of nurses said they could contribute to the quality of pharmacy service. These results were interpreted as an indication that nurses were willing to act as resource persons.

There was some identification of needs of nurses and areas where pharmacists could be helpful. Over one-half of the nurses said they could never learn all they needed to know about the drugs they administered to their patients, and those were the nurses who used the largest variety of 
drugs. The preliminary survey pointed out that drug information was a significant need of nurses. Of the list of choices presented, "Drug information with each new order" was the service by pharmacy that most nurses desired, in the final survey. A large number of nurses said they felt most inadequate in the knowledge of which drugs could be used together, and most felt that medication specialists among their own ranks would not benefit their patients.

None of the pharmacy services in the hospitals under study provided a periodic bulletin to nursing nor were there regular ward conferences between pharmacists and nurses. Indeed, poor communications was chosen as the primary cause of most problems. More than 10 per cent of the nurses failed to recognize that they had common problems with pharmacists, which could have been due to poor communication. Periodic bulletins and ward conferences were chosen most often as activities that would improve services. Almost all nurses felt that it was possible for pharmacists to understand the problems of nurses. The preliminary survey showed that the understanding could be accomplished if pharmacists became more active at the patient care level. It was suggested in the final survey that the pharmacists who were held in the highest esteem by nurses were those who were present in the patient care area most often.

A large per cent of nurses felt that writing requisitions and calling physicians about medications were most 
unrelated to their duties as nurses compared with the other choices. These activities were interpreted as areas where expanded pharmacy services might be very welcome by nurses. Nearly one thind of the nurses felt most inadequate in pharmaceutical calculations. Pharmacy services could have been needed in assumption of more calculations for nurses or by partaking in in-service classes for nurses.

Nearly all nurses felt that the purpose of the pharmacy service was to serve the health and well-being of the patient. In essence, that was the primary goal of nursing as described in the preliminary survey. Technical qualities as (1) expertise, (2) accuracy, and (3) efficiency, were the most desired qualities of a pharmacist. Cooperation and concern for others were of secondary importance. This may have revealed something of the priority of values the nurses attached to each other.

Eighty-four per cent of the nurses said that the information they received from pharmacy was adequate, and 89.3 per cent said that the pharmacy was usually helpful when called. However, pharmacy lagged behind the Physicians' Desk Reference and package literature as the best source of information. This showed that pharmacy was inadequate in providing some kind of vital information. The type of information was not identified. Perhaps a part of it was deciding what drugs could be used together. 
Almost one-half of the nurses perceived pharmacists to be interested in what happened in the rest of the hospital, and a nearly equal number thought pharmacists to be poorly-informed or not interested. The fact that only 11 per cent felt their respective pharmacy services to be excellent and patient-oriented suggested that pharmacy services might come closer to being the best sources of information if they became more patient-oriented.

As contact with pharmacists decreased, nurses had a greater tendency to say they had no need to talk to pharmacists. The greatest tendency was among the $11-7$ nurses who had no pharmacy services on that shift. Nurses felt a greater need and tendency to consult with pharmacists when the most pharmacists were provided. A negative feeling toward pharmacy consults may have been caused, in part, by lack of contact.

Significant Differences Between Groups of Nurses

Grouped by hospital. The pharmacies in the smallest two hospitals received the lowest ratings as the best sources of information. The nurses in the same hospitals conferred the least for drug information with their pharmacists. The nurses in the largest hospitals conferred the most with their pharmacists. This may have suggested relative size of hospitals as an indicator of the ability of the hospitals to provide needed services. The type of hospital might have 
been a factor, since the two largest hospitals were teaching hospitals. It was discussed previously that nurses in the smallest two hospitals expressed a lesser need for pharmacist availability.

The philosophy of administration may have been an influencing factor in the selection of the services that would be most welcome. Upper level nurses in Hospital (1) were unique in their answers; and nurses in Hospitals (3) and (4) answered almost identically. Generally, the "hospital factor" was significant in:

1. Adequacy of information.

2. Which source of information was the best.

3. Whether there was a felt need to talk to a pharmacist.

4. The desirability of medication nurses.

5. The frequency of conferring with pharmacy.

6 . Which services would be most welcome. Grouped by level of supervision. The nurses who had the most patient contact (team leaders) conferred the least with pharmacists. It was concluded that pharmacists were not providing the information that team leaders wanted, or the organizational structure of the hospitals did not allow for adequate interface between pharmacists and team leaders. Grouped by shift. The 7-3 nurses in Hospital (1) rated pharmacy information the least adequate. This was considered significant, because Hospital (I) provided more 
pharmacists than did any other hospital (up to five pharmacists on duty at one time). It was concluded that, from a nursing standpoint, the quality of information could not be equated with numbers of pharmacists alone.

As opportunities for nurse-pharmacist contact decreased, the desire on the part of nurses for bulletins and ward conferences increased. As the opportunities for contact increased, the tendency to say "no need to talk to a pharmacist" decreased. No 3-1l nurses wanted a visit from a pharmacist, and that group had the greatest tendency to perceive pharmacists as not being interested.

Grouped by specialty. Medical nurses had a comparatively high preference for pharmacy as the best source of information, and a comparatively low preference for the Physicians' Desk Reference. Those specialties that handled the greatest varieties of drugs had the greatest tendency to say they could never learn enough about the drugs they administered. Medical nurses were consistently more in favor of medication nurses, while other specialties varied in their answers from hospital to hospital. Nurses who handled the fewest drugs also had the greatest tendency to say "no need to talk to a pharmacist." Surgical nurses conferred the most often. Delivery room nurses conferred the least. Surgical and delivery room nurses expressed a high inadequacy in pharmaceutical calculations. Other differences between 
medical and surgical nurses were mentioned under Discussion, Question (18), and were evident in the preliminary survey. Grouped by experience. As nurses gradually became older, they had better attitudes toward pharmacy services. The popularity of the pharmacy and the Physicians' Desk Reference increased as the years of experience increased. Fewer younger nurses tended to rate the pharmacy service as "excellent" than older nurses. Nurses who had more than 10 years experience tended to perceive pharmacists as being more interested in what happens in the rest of the hospital. It was concluded that pharmacists might have had a general inability to be responsive to the needs of younger nurses. Nurses with more than 20 years of expereince felt that writing requisitions was more related to their duties and phoning physicians was less related. This was evident in both surveys. Nurses with 5-10 years of experience tended to be the least favorable toward the idea of medication nurses.

Grouped by tenure. Nurses who had worked in each hospital for less than one year were less inclined to choose the pharmacy as the best source of information. In general, nurses with the least tenure used the pharmacy consultations less than other nurses. Nurses with more than 10 years of tenure had a tendency to rate the pharmacy services as "excellent." It was suggested that perhaps a process of adjustment to the institution and accumulated experiences with 
pharmacists gradually changed the attitudes of the younger nurses. The conclusion followed that pharmacy services were too slow in meeting the needs of the newer nurses and were not performing up to their expectations.

Grouped by education. University graduates showed high preferences for the pharmacy and formulary as the best sources of information. They were more critical of pharmacists, however, since 68 per cent thought that pharmacists were not interested or not well-informed. University graduates placed higher values on interpersonal contact between pharmacists and nurses. This group of nurses did not deviate significantly from the average in any other results.

Conclusion. Even though the reasons were not clearly defined, there were significant differences in the attitudes of nurses toward their pharmacy services. The differences were characteristic of:

1. Level of supervision.

2. The hospital.

3. Shift worked.

4. Specialty.

5. Education.

6. Years of experience.

7. Tenure. 
Pharmacist Survey

Pharmacists and nurses were in close agreement on several subjects. Both groups agreed on the purpose of pharmacy services. There was a strong agreement about a pharmacist being needed and whether or not he was helpful. Both agreed on the activities that were unrelated to nursing, and that pharmacists could understand the problems of nurses. The agreement was not quite as strong in a number of areas. Pharmacists tended to be more critical of pharmacy services than did nurses. Nurses were more inclined to feel that pharmacists were well-informed than were pharmacists. Nurses were less inclined than pharmacists to feel that nurses could never learn enough about medications and to be in favor of medication nurses. Pharmacists perceived nurses as being adequate in pharmaceutical calculations to a greater extent than did nurses. Both groups thought they should work together, but pharmacists had more of a tendency to feel that nurses could contribute to the quality of pharmacy services. Pharmacists were more inclined to choose technical aspects and cooperation as desirable qualities of pharmacists and were less inclined to choose accuracy than were nurses. Pharmacists had a greater tendency to recognize lack of understanding and communications as the sources of most problems between themselves and nurses.

There was practically no agreement on the adequacy of pharmacy information and what were the best sources of 
information. Also, there was little agreement as to which pharmacy service would be most welcome by nurses and what activities would most benefit both nursing and pharmacy services. In general, most pharmacists thought that a pharmacist available would be the answer, which was not what most nurses said.

\section{Recommendations}

1. Pharmacists and nurses should look for ways to bridge gaps in misunderstanding and communication between each other.

2. It is recommended that more contact between pharmacists and nurses should take place. The cultivation of professional relationships with nurses should be an important part of the pharmacist's role. Contact is especially needed with the following groups of nurses:
a. Newly employed.
b. Less experienced.
c. Nurses with the most patient contact; i.e., team leaders.

3. Pharmacists should spend more time in the patient care area. The implications of this research are that clinically oriented pharmacists provide the most satisfactory services to nurses. Pharmacists will have to free themselves from non-clinical functions and extend themselves into the clinical arena in order to improve their services to nurses. Nurses are willing to act as resource persons. 
4. Pharmacists should evaluate present services in view of the possibility that the services are inadequate. Pharmacists in hospitals of less than 150 beds should be especially concerned about the quality of their services. This is not necessarily a function of numbers of pharmacists on the staff.

5. Pharmacists should recognize that nurses cannot be dealt with collectively; because different specialties, levels of supervision, etc.; have different needs. Techniques must be developed for information delivery to nurses based upon those needs. Bulletins and ward conferences are suggested as examples.

6. Hospital administrators should strive to provide encouragement and opportunities that foster communication and understanding laterally within the hospital structure.

7. Twenty-four-hour pharmacy service seven days a week should be established in all hospitals. 
APPENDIX A

QUESTIONNAIRE USED IN PRELIMINARY SURVEY 
85

Preliminary Questionnaire

This questionnaire is related to a research project to partially fulfill requirements leading to a M.S. degree in hospital pharmacy administration.

Your name has been selected at random by assigning it a number and then drawing numbers out of a hat. The number appears on this paper. Only your supervisor, not the researcher, knows who is completing the questionnaire.

It is desired that you answer all questions honestly and freely; so, do not write your name on the paper and do not return the complete questionnaire to the supervisor. You may use your pharmacy bag to return it to $\mathrm{Mr}$. Anderson in the pharmacy.

Please complete your questionnaire and return it before 11:00 PM on Saturday, August 3. Thank you.

Opettorchudutens 
Page 1

1. I am a ( ) Supervisor ( ) Head nurse ( ) Assistant Head Nurse () Team Leader.

2. I work the ( ) 3-11 shift ( ) 7-3 shift ( ) 11-7 shift

3. I work ( ) hours per week.

4. I work in a ( ) unit. (Surgica1, Medica1, etc.) If float nurse, please indicate.

5. I graduated from a ( ) hospital program ( ) university or college program with a ( ) degree.

6. I have been working ( . ) number of years in nursing.

7. I have been working ( ) number of years in this hospital.

A. What is the general goal of your department?

B. What duties do you now perform which you feel are unrelated to your duties as an R.N. ? 


\section{Page 2}

C. What should you be doing instead ?

D. What services are provided by pharmacy that you feel are helpful?

E. What services could pharmacy perform to help increase the quality of nursing care? 


\section{Page 3}

F. What services could pharmacy perform to help expand your role in therapeutic service to both patient and family?

G. What services could nursing perform to help improve pharmacy services?

H. What do you feel you need to know about drugs ? 


\section{Page 4}

I. What do you feel are the qualities of an effective pharmacist ?

J. Can you usually idantify the reasons for problems that arise between you and pharmacy? Please give examples. 
Page 5

$\mathrm{K}$. What tools or techniques have you devised to improve relations with pharmacy?

L. Is the pharmacy able to recognize your problems ? Please give examples.

M. What standard practices have you devised to avoid problems in handling drugs ? 
Page 6

N. How can the pharmacist become adequately knowledgeable of the forces involved in patient care which tend to influence your work? 
APPENDIX B

QUESTIONNAIRE USED IN FINAL SURVEY 


\section{THE UNIVERSITY OF ARIZONA}

TUCSON, ARIZONA 85721

COLLEGE OF PHARMACI

Apri1, 1969

Dear colleague:

This survey is part of a research project being conducted in partial fulfillment of requirements leading to a master's degree in hospital pharmacy administration. Your cooperation is essential to the success of this project.

Please read each question and all answers carefully before answering. Take your time and please give thoughtful answers. All questions must be answered. Choose the answer which is most appropriate.

Please return the questionnalre within ten days in the stamped, self-addressed envelope. There is no need to sign your name.

Thank you very much for taking time to particlpate in this research project.

Sincerely,

gxatbiludelusan

Keith K. Anderson, B.S., R.Ph. 
A. I am a () Head Nurse ( ) Assistant Head Nurse () Team Leader

B. I work the () 7-3 shift ( ) 3-11 shift ( ) 11-7 shift

C. I work in a setting which is

( ) Surgical

() Medical

() O.B.

() Labor and Delivery

( ) E.R.

( ) Pediatric

( ) Nursery

( ) Intensive Care Unlt

() Varlable

D. I () Do ( ) Do not have a baccalaureate degree.

E. I have been in nursing

() Less than 5 years

() Between $5-10$ years

( ) $11-20$ years

() More than 20 years

F. I have worked in this hospital

( ) Less than one year

( ) Between one and ten years

( ) Ten or more years.

PLEASE CIIECK ONLY ONE ANSWER TO EACH QUESTION:

1. Information supplfed by pharmacy is

() Adequate

( ) Inadequate 
2. The best source of drug information is

( ) P.D.R.

(') Hospital Formulary

( ) Package information

(.) Pharmacy

3. Pharmacy, when called, is:

() Usually helpful

( ) Usually helpful, but bothered by questions

(.) Usually, not helpful

( ) Usually not helpful, and bothered by questions.

4. The best time on my shift for a pharmacist to viait and talk over my problems is

( ) Early

( ) Late

( ) Middle hours

() No need to talk to a pharmacist

5. I can never learn all that I should know about the medications that I am now giving to my patients.

() True () False.

6. I feel that if I were strictly a medication nurse, the patient would benefit from my specialty.

(.) True () False

7. I feel that

( ) The pharmacist should not be concerned with the problems of nursing and should concentrate on the problems of pharmacy.

() The pharmacist is needed outside the four wallo of the pharmacy and should be concerned with what happens at the nursing unit. 
8. The activity that would most improve nursing and pharmacy services is

( ) Ward conferences between pharmacists and nurses.

( ) A periodic, regular bulletin from pharmacy concerning new drugs, policies and procedures, etc.

() Visitation at the nursing untt at regular, specified times by pharmacy personnel.

( ) A nurge working for a day or two in the pharascy as part of an orientation process.

( ) A pharmacist working for a day or two at the nursing unit for a day or two as part of an orientation process.

9. The activity which is most unrelated to the duties of an R.N. is

() Preparing medications.

() Passing medications.

( ) Spending time on the telephone calling doctors with medication questions.

( ) Mixing I.V. solutions.

( ) Diluting injectable medications.

() Writing drug requisitions.

10. I confer with a pharmaclst for drug information
() Seldom

( ) Never

() often

11. I feel the least adequate in the area of

\section{() Pharmaceutical calculations}

( ) Knowledge of the side effects of a drug

( ) Knowledge of what the drug can be expected to do

( ) Knowledge of contraindications for use of a drug

( ) Knowledge of which drugs can be used together

( ) Knowledge of uaual dosage range. 
College of Pharmacy Survey

Page 4

Apr11, 1969

12. The purpose of pharmacy service should be to first

( ) Serve the conventence of the physician

( ) Serve the conventence of the nurse

() Serve the health and well being of the patlent

( ) To not complicate the pleture at the patient level.

19. The service which would be most welcome is

() Drug Information supplied with each new drug order

( ) I.V. additive service

(.) A pharmacist avallable to answer questions

() Pre-diluted injectable materials

14. Pharmacy service in this hospital is

() Excellent

() Adequate

() Not very good

() Excellent, and patlent ortented

15. What I dislike most about handing drugs is

( ) I feel insecure and Inadequate

( ) It to time wasting and keeps me away from bedside nursing

16. I belleve that

( ) Pharmacists and nurses should work together

( ) There is a need for nurses and pharmacists to work together, and nurses can contribute to the quality of pharmacy service.

() There is no need for pharmacists and nurses to work together.

() I need help in my work, but pharmacy should not be helper.

17. I feel that

( ) Pharmacists are not interested In what happens in the rest of the hospital.

( ) Pharmacists are interested but poorly informed.

( ) Pharmacists are interested and well informed. 
18. The most desirable quality of a pharmacist is

( ) Befing expert and efficient in the technical aspects of his work.

( ) Showing concern for others.

() A cooperative attitude.

( ) Being knowledgeable about drugs.

() Accuracy.

() Being an independent thinker.

19. Most problems with pharmacy arise because

( ) We do not understand each other's work.

() There are too many technicalities and petty rules.

( ) No problems.

() Poor communications exist on a staff level.

20. The pharmacist can never understand the problems associated with nursing.
( ) True
( ) False 
APPENDIX $C$

SAMPLE CODING SHEET USED

IN FINAL SURVEY 
NUMERICAL ANALI

PROJECT NO

CODED BY

Q9

DATE

REMARKS (TYPE OF CARD, INTERPRETING, LISTING, ETC.)

Batch \pm 2

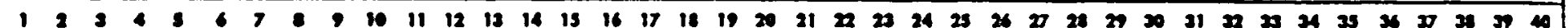

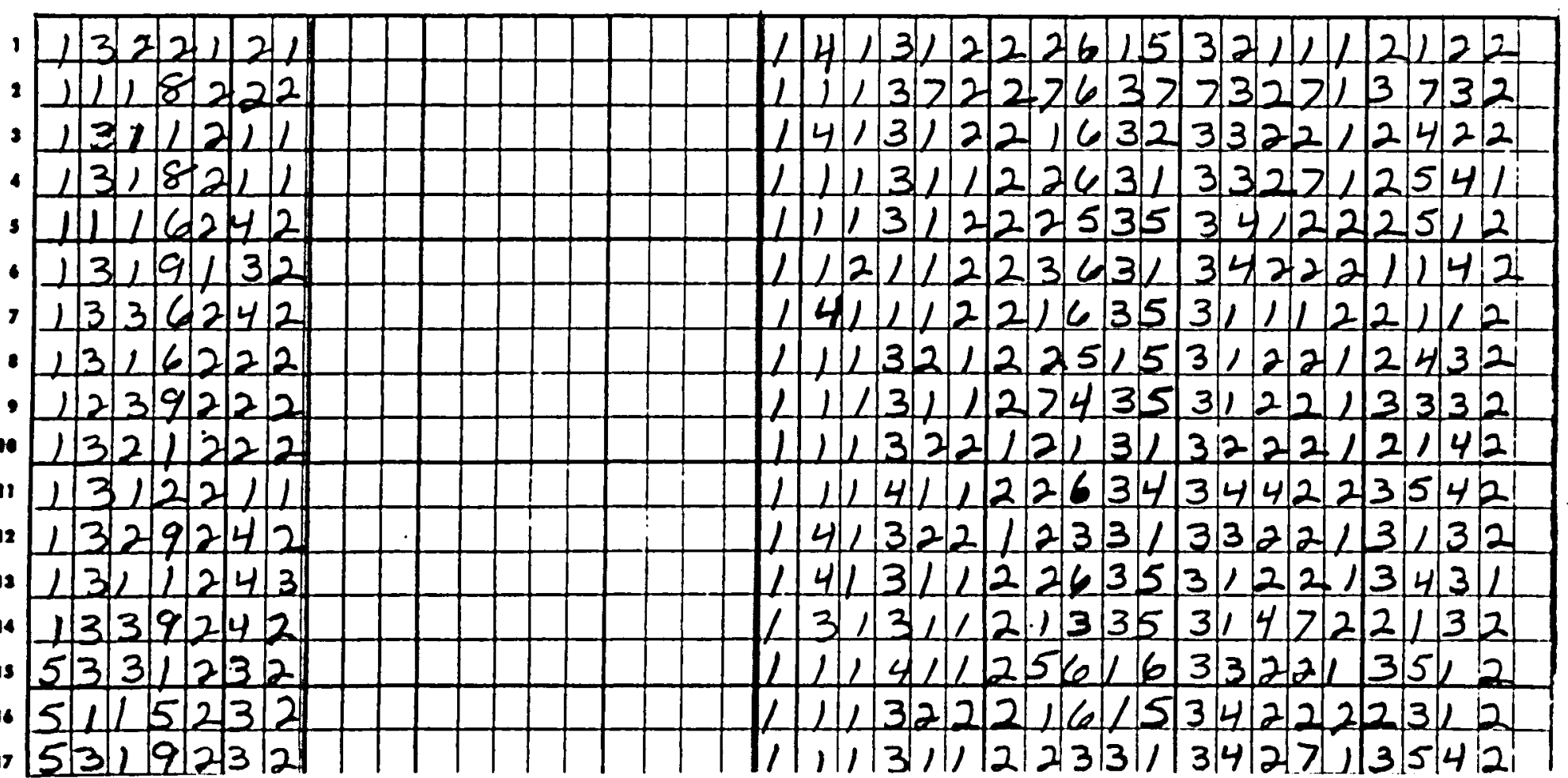


APPENDIX D

SAMPLE HOLLERITH CARD USED IN FINAL SURVEY 


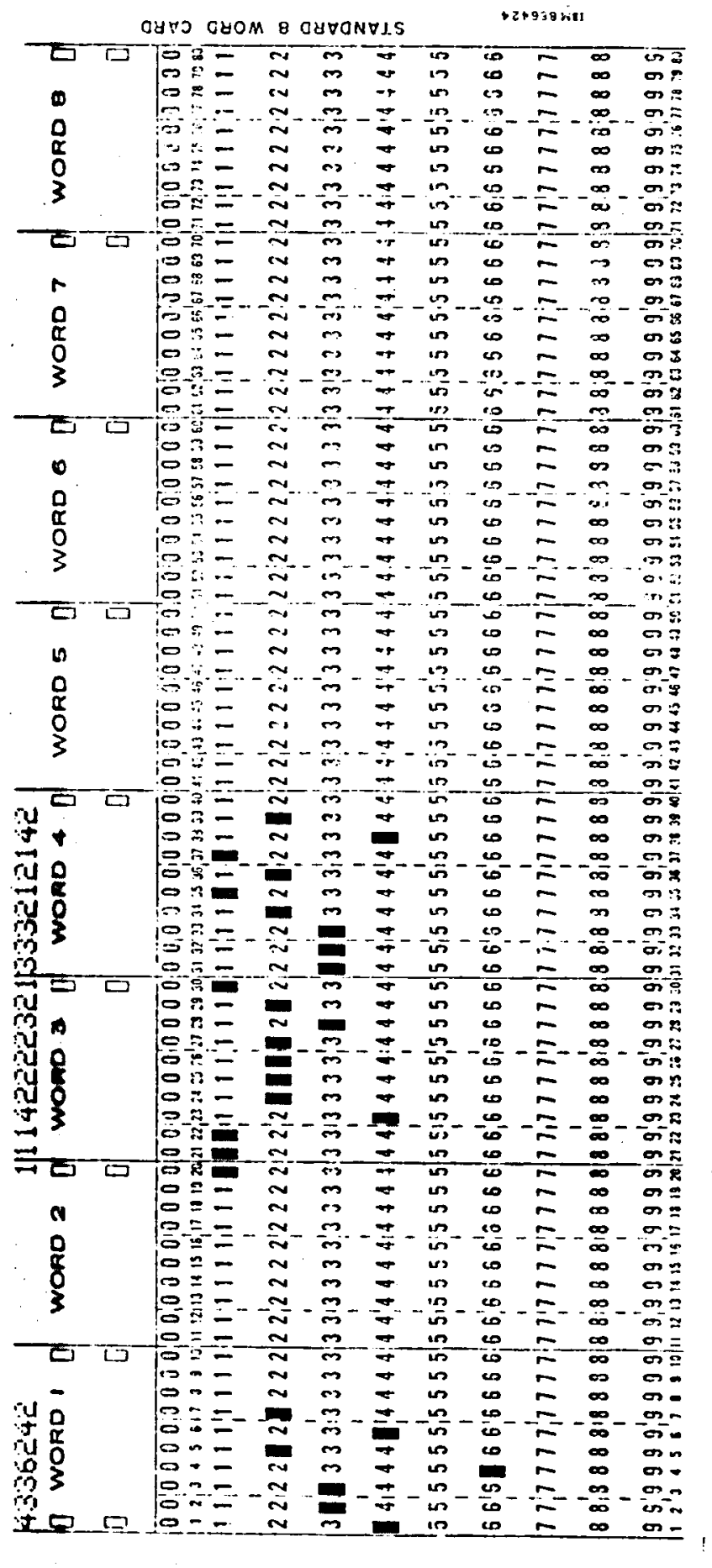


APPENDIX E

SAMPLE COMPUTER OUTPUT, FINAL SURVEY 







\section{APPENDIX F}

QUESTIONNAIRE USED IN

PHARMACIST SURVEY 


\section{THE UNIVERSITY OF ARIZONA}

TUCSON, ARIZONA 85721

COLLEGE OF PHARMACY

Apr 11, 1969

Dear colleage:

This survey is part of a research project being conducted in partial fulfillment of requirements leading to a master's degree in hospital pharmacy administration. Your cooperation is essential to the success of this project.

please read each question and all answers carefully before answering. Take your time and please give thought ful answers. Al1 questions must be answered. Choose the answer which is most appropriate.

Please return the questionnalre within ten days in the sta.uped, self-addressed envelope. There is no need to sign your name.

Thank you very much for taking time to participate in this research project.

Sincerely,

Dethorelunderen

Kefth $K$. Anderson B.S., R.Ph. 
1. Information supplied by pharmacy service is
( ) Adequate
() Inadequate

2. The best source of drug information for the R.N. is

( ) P.D.R.

() Hospital formulary

() Package information

( ) Pharmacy

3. Pharmacy, when called by the R.N., is

(. ) Usually helpful

( ) Usually helpful, but bothered by questions

( ) Usually, not helpful

( ) Usually not helpful, and bothered by questions.

4. Nurses real1, have no need to talk to a pharmacist on nursing station visits.
( ) True
( ) False

5. The nurse can never learn all she should know about the medications she is giving her patients. () True () False

6. The patient would benefit if some nurses were strictly medication nurses.
( ) True
( ) False

7. I feel that

( ) The pharmacist should not be concerned with the problems of nursing and should concentrate on the problems of pharmacy.

( ) The pharmacist is needed outside the four walls of the pharmacy and should be concerned with what happens at the nursing unit. 
8. The activity that would most improve nursing and pharmacy services is

( ) Ward conferences between pharmacists and nurses.

() A perlodic, regular bulletin from pharmacy concerning new druga, pollcies and procedures, etr.

( ) Visitation at the nursing unit at regular, specified times by pharmacy personnel.

( ) A nurse working for a day or two in the pharmacy as part of an orientation process.

() A pharmacist working for a day or two on the nursing unit as part of an orientation process.

9. The activity which is most unrelated to the duties of an R.N. is

( ) Preparing medications

( ) Passing medications

( ) Spending time on the telephone calling physicians with medication questions.

( ) Mixing I.V. solutions

( ) Diluting injectable medications

() Writing drug requisitions

10. Most nurses are the least adequate in the area of

( ) Phamaceutical calculations

( ) knowledge of the side effects of a drug

( ) Knowledge of what a drug is expected to do

( ) knowledge of contraindications for use of a drug

() Knowledge of what drugs can be used together

( ) knowledge of ususal dosage range 
11. The purpose of pharmacy service should be to first

( ) Serve the conventence of the physician

( ) Serve the convenience of the nurse

() Serve the health and well being of the patient

( ) To not complicate the picture at the patient level

12. The service that would be wost welcome by nurses is

( ) Drug information with each new drug order

( ) I.V. additive service

( ) A pharmacist avallable to answer questions

( ) Pre-diluted injectable materials

13. Pharmacy service in this hospital is
( ) Exce1lent
( ) Adequate
( ) Not very good
( ) Excellent and patient orlented

14. I belleve that

() Pharmacists and nurses should work together

( ) There is a need for pharmactsts and nurses to work together, and nurses can contribute to the qualitiy of pharmacy service.

( ) There is no need for pharmaclsts and nurses to work together.

( ) Nurses need help in their work, but it should not come from pharmacy.

15. I feel that

( ) I am not really very interested in what happens in the rest of the hospltal.

( ) I an interested but not very well informed.

( ) I am interested and well informed. 
16. The most desirable quality of a pharmacist is

() Being expert and efficient in the technical aspects of his work.

() Showing concern for others.

() A cooperative attitude.

() Belng knowledgeable about drugs.

() Accuracy.

() Being an independent thinker.

17. Most problems with nurses arise because

( ) We do not understand each other's work.

() There are too many technicalities and petty rules.

( ) No problems.

( ) Poor communications exist on a staff level.

18. The phamacist can never understand the problems associated with nursing.
( ) True
() False 
Arndt. "Administrative Factors in Nursing that May Inhibit Job Effectiveness," Journal of Nursing Education, January 1968, Vol. 7, p. 33-43.

Baziak, A. T. "Influencing Nursing Practice in Changing Hospital Settings," Nursing Research, March-April 1968, Vol. 17, No. 2, p. 146-154.

Benne, K. C., and W. Bennis. "The Role of the Professional Nurse," American Journal of Nursing, February 1959, Vol. 59 , No. 2, p. 196 .

- "What Is Real Nursing?" American Journal of Nursing, March 1959, Vol. 59, No. 3, p. 380-383.

Bowden, E. "Nurses' Attitudes Toward Hospital Nursing Services," Nursing Research, Summer 1967, Vol. 16, No. 3, p. $246-251$.

Brodie, D. C. "Trends in Pharmaceutical Education," American Journal of Nursing, September 1968, Vol. 68, No. 9, p. 1948-1951.

Carlin, H. "Decentralized Dispensing System Brings Pharmacist to Nursing Floor," Hospital Topics, December 1966, p. $81-83$.

Cass, D. E. "Expectations of the Staff Nurse in Nursing Practice," Nursing Clinics of North America, March 1968, Vol. 3, No. 1, p. 111-115.

Corwin, R. G., M. J. Taves, and J. E. Haas. "Professional Disillusionment," Nursing Research, Summer 196I, Vol. 10, No. 3, p. 141-144.

Costello, C. G. "Attitudes of Nurses to Nursing," Canadian Nurse, June 1967, p. 42-44.

Dichter, E. "What the Patient Really Wants from the Hospital," Modern Hospital, September 1954, Vol. 83, No. 3, p. 51 .

Dodge, J. S. "Nurse-Doctor Relations and Attitudes Toward the Patient," Nursing Research, Winter 1960, Vol. 9, No. $1, \mathrm{p} .32-3 \overline{8}$. 
Georgopoulos, B. S. "Some Basic Problems and Issues," Nursing Forum, 1966 , Vol. 5, No. 3, p. 8-35.

Goldstein, J. "Exploring Attitudes that Affect Nursing Care," Nursing Outlook, June 1968, p. 50-51.

Hadley, B. J. "Autocratic versus Democratic Beliefs of Graduate Nurses in Nursing," Nursing Research, JanuaryFebruary 1968, Vol. 17, p. 19-26.

Harrington, H. A. and E. C. Theis. "Institutional Factors Perceived by Baccalaureate Graduates As Influencing Their Performance As Staff Nurses," Nursing Research, May-June 1968, p. 228-235.

Henderson, C. K. "The Dispensing Trilemma," American

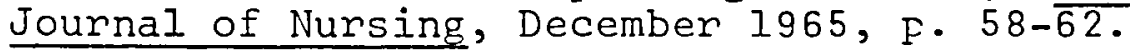

Hohloch, F. J. "Developing an Attitude Inventory," Journal of Nursing Education, August 1968, Vol. 7, p. 9-13.

Johnson, J. E., R. G. Duna, and B. A. Johnson. "Interpersonal Relations: The Essence of Nursing Care," Nursing Forum, 1967, Vol. 6, No. 3, p. 324-334.

Kemp, E., and J. Peitchinis. "Nurses Attitudes: Fact or Fallacy?" Canadian Nurse, February 1968, p. 51-54.

Kramer, M. "Comparative Study of Characteristics, Attitudes, and Opinions of Neophyte British and American Nurses," International Journal of Nursing Studies, 1967, Vol. 4, . p. 281-294.

. "Role Models, Role Conceptions, and Role Deprivations," Nursing Research, March-April 1968, Vol. 17, No. 2, p. $115-120$.

Lancaster, A. "The Reluctant Profession," International Nursing Review, December 1967, Vol. 14, No. 6, p. 25-32.

Lentz, E. M., and R. G. Michaels. "Comparative Ratings of Medical and Surgical Nurses," Nursing Research, Fall 1960, Vol. 9, No. 4, p. 198-202.

- "Personality Contrasts Among Medical and Surgical Nurses," Nursing Research, Winter 1965, Vol. 14, No. 1, p. $43-48$.

Nightingale, C. H. "Distribution of Drugs on the Nursing Unit," Nursing Forum, 1965, Vol. 4, p. 93-97. 
Olson, M. E. "Comparison of Head Nurse and Staff Nurse Attitudes Toward Various Aspects of Nursing Care," Nursing Research, July-August 1968, Vol. 17, No. 4, p. 349-353.

Pearlin, L. I. "Alienation from Work, A Study of Nursing Personnel," American Sociological Review, 1962, Vol. 27, p. 314 .

Peeples, E. H., and G. M. Francis. "Social-Psychological Obstacle to Effective Health Team Practice," Nursing Forum, 1968, Vol. 7, No. I, P. 28-37.

"Pharmacists Realign Goals with New Laws, Health Programs," Hospitals, J.A.H.A., July I, 1968, Vol. 42, p. 75-76.

Quint, J. "Pharmacy Can Help Nursing Control Medication Errors," Hospital Topics, July 1966, p. 93-96.

Reece, M. M. "Personality Characteristics and Success in a Nursing Program," Nursing Research, Summer 1961, Vol. 10, No. 3, P. $172-176$.

Rutherford, R. "What Bothers Staff Nurses," American Journal of Nursing, February 1967, Vol. 67, No. 2, p. 315-318.

Saunders, L. "The Changing Role of Nurses," American Journal of Nursing, September 1954, Vol. 54, No. 9, p. 1094-1098.

Searle, C. S. "Extracts from: 'Personal and Professional Attitudes, " International Nursing Review, JanuaryFebruary 1967, Vol. 14, No. 1, P. 34.

Selmanoff, E. D. "Strains in the Nurse-Doctor Relationship," Nursing Clinics of North America, March 1968, Vol. 3, No. 1, p. 117-127.

Smith, K. "Discrepancies in the Role-Specific Values of Head Nurses and Nursing Educators," Nursing Research, Summer 1965, Vol. 14, No. 3, p. 196-202.

Snodgrass, J. "Interprofessional Stereotyping in the Hospital," Nursing Research, Fall 1966, Vol. 15, No. 4, p. $350-354$.

Spaney, E. "Theories of Attitude Measurements," Nursing

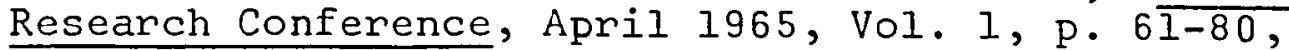
85,87 . 
Stacey, J. "R.N.'s Tell Why They Took Off Their Caps," The Modern Hospital, January 1967, p. 76-77.

Summers, J. "Nurse and Pharmacist-Partners," The Canadian Nurse, February 1967, p. 40-44.

Walker, V. H. "Ritualism in Nursing and Its Effect on Patient Care," A Final Report to the Public Health Service, Indianapolis, Indiana, 1964 (Multilithed).

Van, G. "Nursing Attitudes," Canadian Hospital, July 1963, Vol. 40, p. $41-43$.

Zaccharia. "Nursing Students' Attitudes Toward Their Career--A Challenge for Nursing Education," Journal of Nursing Education, August 1966, Vol. 5, p. 31-34.

7immer, M. J. "A Study to Determine the Readiness of Nurses to Use Independent Judgment in Determining What to Tell and Teach Patients about Medicines," League Exchange, 1967 , Vol. 80, p. 1-114.

Zungolo, E. "A Study in Alienation," Nursing Forum, 1968, Vol. 7, No. 1, p. 38-49. 
